\title{
Tuning Electronic and Magnetic Properties in Graphene Oxide - Porphyrins Complexes
}

\author{
Kornelia Lewandowska ${ }^{1, *}$, Natalia Rosiak ${ }^{2}$, Andrzej Bogucki ${ }^{1}$, Judyta Cielecka- \\ Piontek ${ }^{3,{ }^{*},}$ Mikołaj Mizera ${ }^{3}$, Waldemar Bednarski ${ }^{1}$, Maciej Suchecki ${ }^{4}$ \\ Institute of Molecular Physics, Polish Academy of Science, ul. Smoluchowskiego 17, 60- \\ 179 Poznań, Poland \\ 2
}

Faculty of Technical Physics, Poznan University of Technology, ul. Piotrowo 3, 60-965 Poznań, Poland

3

Department of Pharmacognosy, Faculty of Pharmacy, Poznań University of Medical Sciences, Święcickiego 4, 60-781 Poznań, Poland

4

Academic Centre for Materials and Nanotechnology, AGH University of Science and Technology, Al. Mickiewicza 30, 30-059 Kraków, Poland

\section{Abstract}

:

Graphene oxide (GO) was modified by two modified porphyrins (THPP and TCPP) to form GO-porphyrin hybrids. Spectroscopic measurements demonstrated the formation of stable supramolecular aggregates when mixing two components in solution. The Fourier transform infrared (FTIR) and Raman scattering measurements confirm m-stacking between hydrophobic regions of GO nanoflakes and porphyrin molecules. On the number and the kind of paramagnetic centers generated in pristine GO samples, which originate from spin anomalies at the edges of aromatic domains within GO nanoflakes. More significant changes in electronic properties have been observed in hybrid materials. This is particularly evident in the drastic increase in the number of unpaired electrons for the THPP-GO sample and the decrease in the number of unpaired electrons for the TCPP$\mathrm{GO}$. The difference of paramagnetic properties of hybrid materials is a consequence of $\pi-$ stacking between $\mathrm{GO}$ and porphyrin rings. An interesting interplay between modifiers and the surface of $\mathrm{GO}$ leads to a significant change in electronic structure and magnetic properties of the designed hybrid materials. Based on the selection of molecular counterpart we can affect the behavior of hybrids upon light irradiation in a different manner, which may be useful for the applications in photovoltaics, optoelectronics, and spintronics. Keywords:

porphyrins-GO complexes; magnetic material; charge transfer 


\section{Introduction}

Graphene has many record properties. It is transparent like (or better than) plastic, but conducts heat and electricity better than any metal, it is an elastic film, behaves as an impermeable membrane, and it is chemically inert and stable [1]. Large scale production of graphene is still expensive and difficult, however simple oxidative treatment of pure graphite results of formation of well known, but still somehow mysterious compoundgraphite oxide. Under ultrasonic treatment in polar solvents and in the presence of bases it can be exfoliated and dissolved [2]. This new material is usually called graphene oxide (GO). It consists of single nanoflakes of graphene highly decorated with oxygen-containing functional groups. This material, upon deposition on solid substrates shows semiconducting properties $\left(E_{g} \sim 2.2 \mathrm{eV}\right)$ with low charge carrier mobility. Graphene oxide is an universal bonding platform well suited for covalent and non-covalent modifications due to the presence of various functional groups (hydroxyl, epoxy, carboxyl, carbonyl) and aromatic domains [3,4,5]. Graphene oxide (GO) and reduced graphene oxide (rGO) based composite with porphyrins are found to be promising materials for light energy conversion, optoelectronics, and photovoltaics because carbon nanomaterials can serve as charge carrier scavengers and molecular-scale conductors, thus facilitating the charge transfer processes involving porphyrin molecules $[6,7,8,9,10,11,12,13]$.

The porphyrins can form the hybrid structure with $\mathrm{GO}$ due to various non-covalent interactions such as hydrogen bonding, $\pi-\pi$ stacking, hydrophobic interactions, electrostatic interactions, van der Waals forces. etc. Compared with covalent functionalization, noncovalent methods through supramolecular interactions have the advantage of maintaining the unique electrochemical properties of $\mathrm{GO}$ and porphyrins as well as simplicity of their fabrication and/or further modification [14]. Recently, noncovalent functionalization of GO has shown exciting potential in terms of loading efficiency and manipulation $[15,16]$. GO can be easily modified with various redox-active compounds [17] and other carbon nanostructures, including carbon nanotubes [18]. The interest in noncovalent functionalization of GO with porphyrins in particular results from the fact that porphyrins form a planar 18-pi electron ring or macrocycle, have extremely high molar absorption coefficients and show numerous potentially useful photochemical and photophysical properties, including photoinduced energy and electron transfer processes $[19,20]$. More importantly, it is possible to endow optoelectronic properties of $G O$ when it is combined with planar aromatic molecules such as porphyrins and phthalocyanines [21,22].

The noncovalent stacking of aromatic organic molecules on graphene oxide through $\pi-\pi$ interaction is emerging as a promising route to tailor the electronic properties of graphene oxide. In graphene oxide- core-modified-porphyrins and expanded porphyrin hybrids are observed an enhanced nonlinear optical response.

Therefore, in this paper we investigate interactions between graphene oxide and two free-metal porphyrins using various spectroscopic techniques supplemented with quantum-chemical modeling. The basic understanding on the electronic interaction of meso-substituted porphyrin molecules with graphene oxide is very important to design promising devices. In the present work we provide a simple route of preparation of a GOporphyrin assemblies. A hydrophobic porphyrin derivative was combined with $\mathrm{GO}$ on the 
basis of affinity of p-electron systems $[23,24]$. The formation of GO-porphyrin composite has been well characterized by ultraviolet-visible spectroscopy (UV-Vis), Fourier transform infrared (FTIR) spectroscopy, Raman scattering and electron paramagnetic resonance (EPR) measurements. The main aim of the study is to understand the nature of interaction between the components as well as elucidate the electronic structure of these new supramolecular entities and the nature of the electron/energy transfer processes between constituents within supramolecular assemblies.

\section{Results and Discussion}

\subsection{Optical Spectroscopy}

The absorption spectra of the two porphyrins THPP and TCPP show a typical Soret band and four $Q$ bands (Figure 1a). The strong band at $422 \mathrm{~nm}$ for THPP and at $418 \mathrm{~nm}$ for TCPP was assigned to the Soret band arising from the transition to the second excited state (S0 $\rightarrow$ S2) and the other four absorption maxima at 518, 556, 595, and $652 \mathrm{~nm}$ for THPP; 514, 549, 589, and $645 \mathrm{~nm}$ for TCPP were attributed to the $Q$ bands corresponding to weak transition to the first excited state $(\mathrm{S} 0 \rightarrow \mathrm{S} 1)$. The Soret and the $\mathrm{Q}$ bands both arise from $\pi-\Pi^{*}$ transitions and can be explained by considering the four frontier orbitals (HOMO and LUMO orbitals) $[25,26]$.

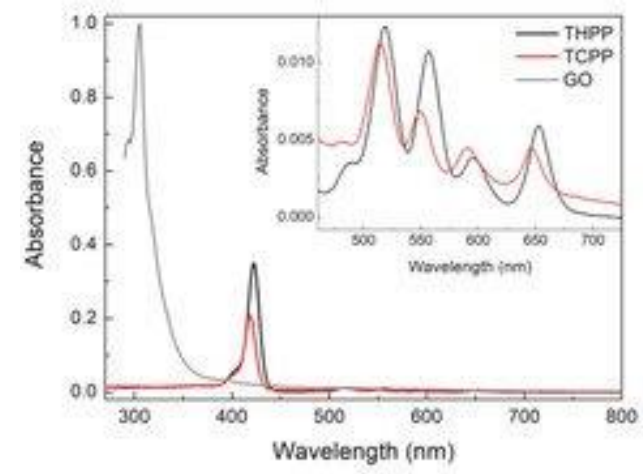

(a)

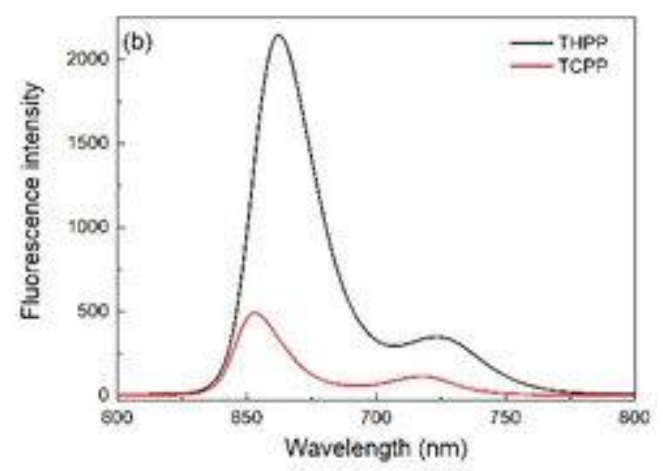

(b)

Figure 1. Absorption (a) and fluorescence (b) spectra of two porphyrins THPP (black) and TCPP (red).

The UV-Vis absorption spectra of $\mathrm{GO}$ are characterized by two peaks at $232 \mathrm{~nm}$ and $295 \mathrm{~nm}$. The first peak comes from the $\pi-\pi^{*}$ transition and is related to the $C=C$ bond in an aromatic ring and the second one is due to the $n-\pi^{*}$ transition of the $\mathrm{C}=\mathrm{O}$ bond $[27,28,29]$.

The fluorescence spectra of the metal-free porphyrins at a concentration of about $10^{-6} \mathrm{M}$ are shown in Figure $1 \mathrm{~b}$. It can be seen that studied porphyrins display two emission peaks at 663 and $726 \mathrm{~nm}$ (THPP); 653 and $716 \mathrm{~nm}$ (TCPP), respectively. This spectral pattern is characteristic for the monomeric porphyrin molecules. Comparing the fluorescence spectra of THPP and TCPP one can observe, that the luminescence intensity of THPP is much stronger than that of TCPP. This is caused by hydroxyl and carboxyl groups in the two porphyrins, which influence the increase and decrease in the average electron density of the conjugated porphyrin system, respectively. It causes the facilitation 
of the intersystem crossing (ISC) of $\mathrm{S} 1 \rightarrow \mathrm{T} 1$, therefore the fluorescence intensity of TCPP is weaker compared to the case of THPP [30].

Figure 2a shows the UV-vis spectra of the porphyrins-GO complexin the presence of different concentrations of GO. With a gradual increase of $G O$ in the hybrid systems, absorption peak positions undergo small changes of about 1-2 $\mathrm{nm}$. This observation suggests that the porphyrin geometry is not altered after the composite formation with GO, especially that the supramolecular interaction does not induce any significant structural deformations of porphyrin molecules. It also indicated that the stacking attachment of the GO moiety has not perturbed the ground electronic state of the porphyrin and is strong enough to make the material stable also in the solid state. These results corroborate not only the non-covalent linkage of porphyrin with the GO sheets but also electronic interaction between the two species in the ground state [31]. The alternative aggregation potential induced by the $\mathrm{H}$ bond is excluded because no significant shifts in the absorption bands have been observed and this is further substantiated by IR and Raman spectroscopies. These results indicate that electrostatic interaction has a weak effect on the supramolecular assembly of porphyrins molecules on GO [32]. These results are in agreement with studies based on other hybrid systems consisting of porphyrins covalently grafted to carbon nanotubes and nanohorns [33,34,35,36,37,38,39].

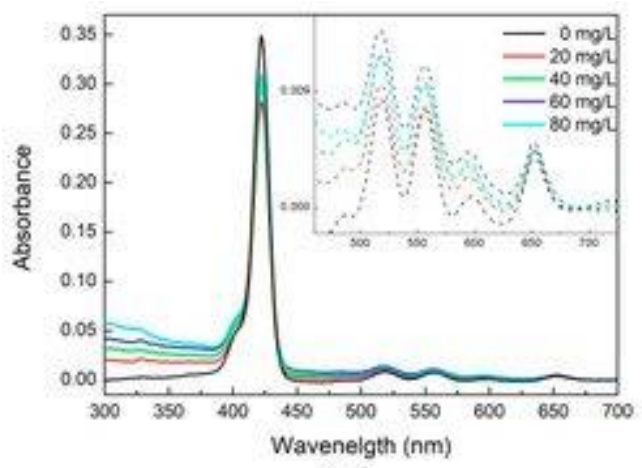

(a)

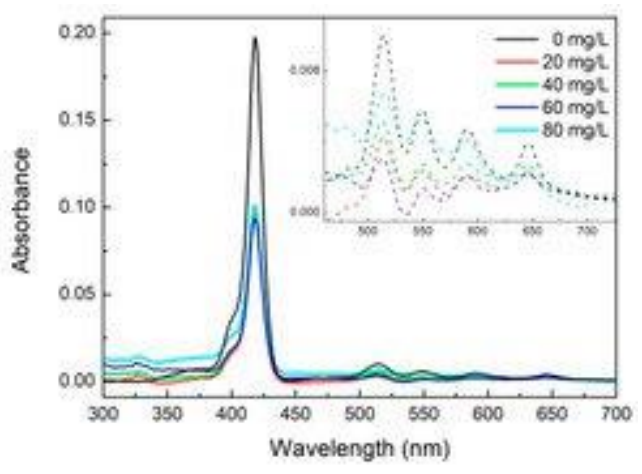

(b) 


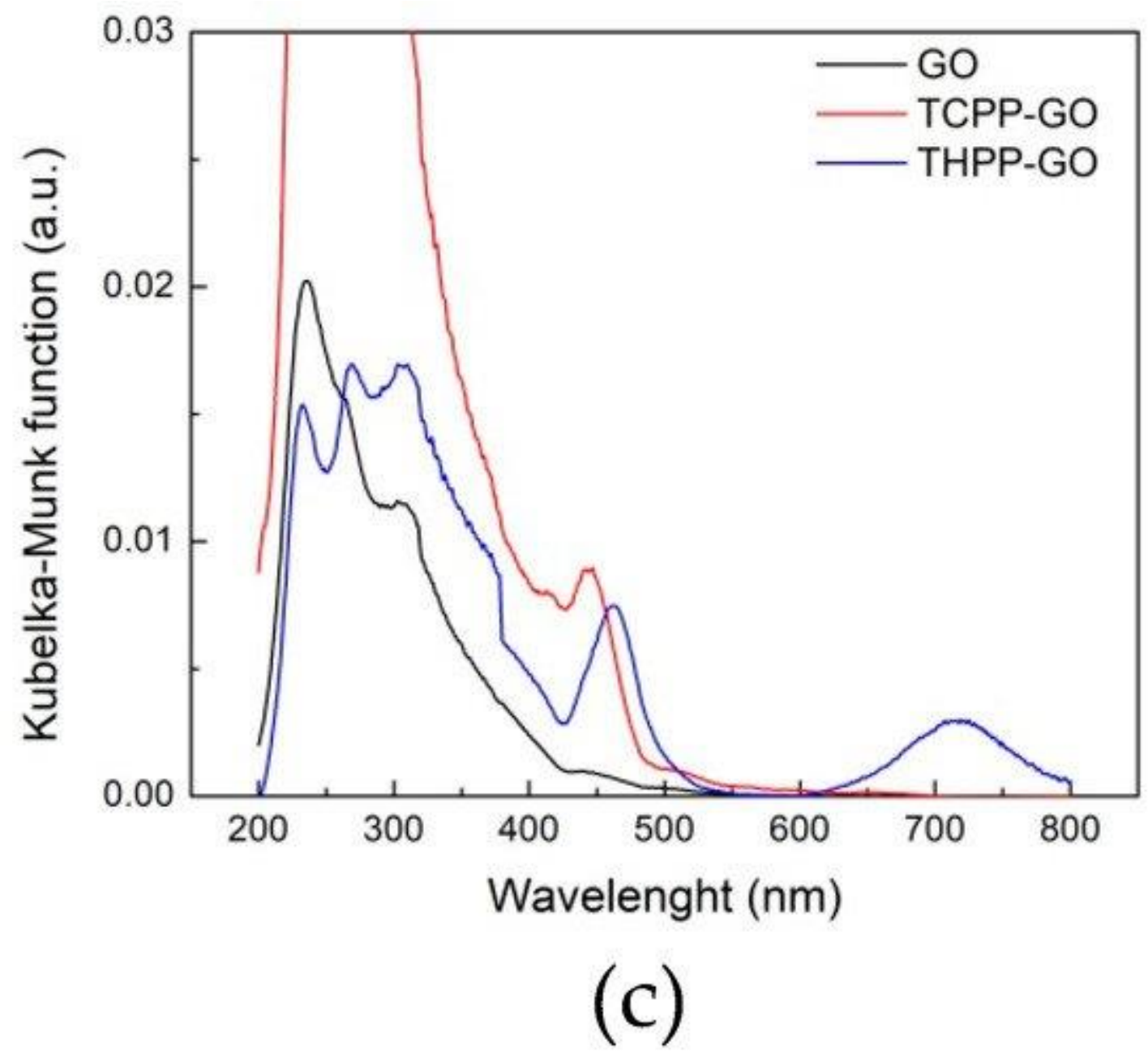

Figure 2. Ultraviolet-visible spectroscopy (UV-Vis) spectra of metal-free porphyrins THPP (a), TCPP (b), 10-4 $\mathrm{M}$ with graphene oxide $(G O)$ in different concentrations of $\mathrm{GO}$ red-20 $\mathrm{mg} / \mathrm{L}$, green-40 mg/L, blue—60 mg/L, cyan—80 mg/L. Diffuse reflectance spectra of GO, TCPP-GO and THPP-GO supramolecular assemblies isolated as a solid phase (c).

To further demonstrate that porphyrins could be assembled onto the GO, we used fluorescence spectroscopy to investigate the GO-porphyrin systems. Figure 3 shows the fluorescence spectra of two metal-free porphyrin-GO complexes formed in various concentrations of GO at the excitation wavelength of $418 \mathrm{~nm}$. THPP, TCPP have a broad emission comprising of two unresolved $Q(0,0)$ and $Q(0,1)$ bands at ca. 663 and $726 \mathrm{~nm}$ (THPP); 653 and $716 \mathrm{~nm}$ (TCPP), respectively. Vergeldt et al. postulated that coalescence of the Q-bands is caused by the mixing of the first excited-state $\mathrm{S} 1$ of the porphyrin and the charge transfer (CT) state in which an electron is transferred from the porphyrin macrocycle to the pyridinium substituent of the porphyrin. For coplanar orientation of the pyridinium groups and the porphyrin macrocycle, electronic coupling between the $\mathrm{S} 1$ and the CT states increases [40]. For our material a similar case takes place and the electron must be transferred from the porphyrin macrocycle to the peripheral aryl groups. 


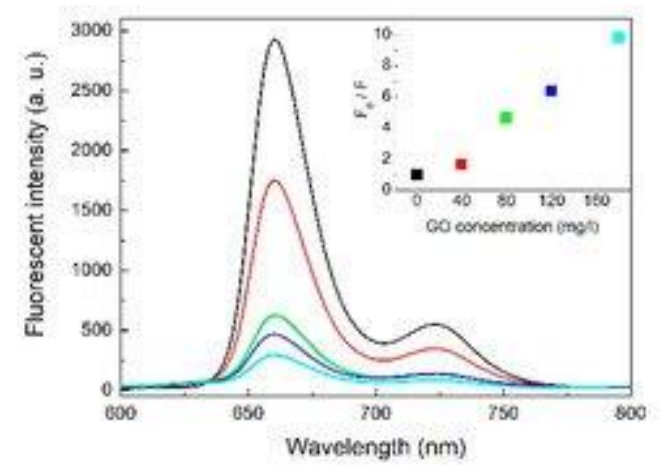

(a)

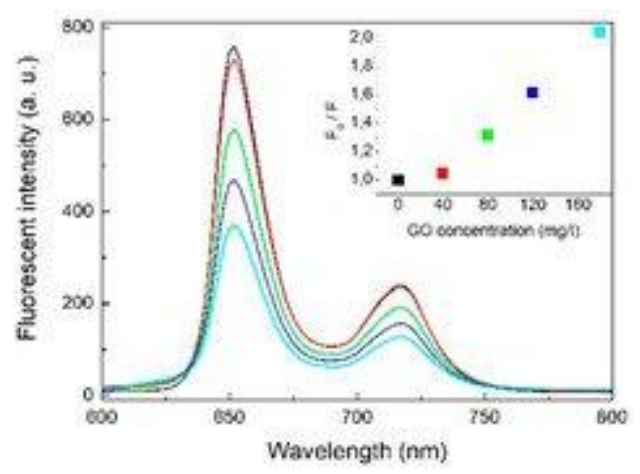

(b)

Figure 3. Fluorescence spectra of two metal-free porphyrins THPP (a) and TCPP (b), with different concentrations of GO red-20 mg/L, green $-40 \mathrm{mg} / \mathrm{L}$, blue $-60 \mathrm{mg} / \mathrm{L}$, cyan -80 $\mathrm{mg} / \mathrm{L}$.

For the porphyrins-GO systems the emission peak positions remain unchanged, but the photoluminescence intensity decreases with increasing concentrations of $\mathrm{GO}$, which indicates the existence of free and adsorbed porphyrins in equilibrium. The plot of $F_{0} / F$ to $Q$ (quencher concentration) is neither linear nor parabolic. Accordingly, the static/dynamic quenching coexisted and related constant were determined from the following Stern-Volmer equation [41]:

$$
\mathrm{F} 0 \mathrm{~F}=1+(\mathrm{Kd}+\mathrm{Ks})[\mathrm{Q}]+\mathrm{Kd} \cdot \mathrm{Ks}[\mathrm{Q}]^{2}
$$

where $F_{0}$ and $F$ denote the fluorescence intensities of the fluorescent substance in the absence and in the presence of quencher concentration of [Q]. $K_{d}$ and $K_{\mathrm{s}}$ are the dynamic quenching constant and static quenching constant, respectively.

The results of the calculation of the THPP-GO was $K_{s}=196.76, K_{d}=0.09$ and of the TCPP-GO $K_{s}=31.61$ and $K_{d}=0.02$, respectively. The $K_{s}$ is much bigger than $K_{d}$. This indicates that non-fluorescent complex formation was the main reason for decreasing fluorescence intensity [42]. The quenching efficiency was calculated as 89 and $51 \%$, for THPP-GO, and TCPP-GO complexes, respectively. This indicates that the THPP derivative interacts stronger with $\mathrm{GO}$ sheets. The fluorescence quenching may be attributed to the photoinduced electron transfer between porphyrin molecules and GO. The Förster energy transfer should be ruled out because there is no significant overlap between the emission spectrum of porphyrin and absorption spectrum of GO. The Dexter mechanism is also not very probable due to the large distance between the counterparts and the lack of any covalent bonds that would provide a platform for electron exchange. This hypothesis is in agreement with the electron transfer from porphyrins to $\mathrm{GO}$ through the $\pi-\pi$ interaction observed in the cases of nanotubes or fullerenes $[37,43,44,45,46,47,48,49]$. These results suggest that the singlet excited state of porphyrin interacts with $\mathrm{GO}$ resulting in a weak or non-emissive complex. Strong interactions between $\mathrm{GO}$ and the excited state of porphyrin, as well as large specific interfacial area in the two dimensional plane of GO might be responsible for attenuated fluorescence emission intensity in the complex via the formation of multiple hetero-junctions between porphyrin and graphene oxide. This efficient quenching of fluorescence emission indicates that the porphyrin-GO complexcan be used 
as an active material for optoelectronic applications working on the basis of photoinduced electron transfer processes. Furthermore, the calculated electronic structure (vide infra) supports this hypothesis.

The electron density of the porphyrins is shown in Figure 4 where the optimized geometries and the HOMO and LUMO surfaces of the studied porphyrins are presented. For the two porphyrins the HOMO orbital is delocalized over the methine bridges and nitrogen atoms. This means that these atoms are the most likely to donate electrons. The main contributing factor to the $\mathrm{HOMO}$ is the porphyrin ring because the substituent groups (in all compounds) appear to have negligible HOMO density. The LUMO orbital is delocalized over the methine bridges and pyrrole rings. DFT calculations indicate that the lower-energy band corresponds to the $\mathrm{HOMO} \rightarrow$ LUMO transition, whereas the band at about $420 \mathrm{~nm}$ corresponds to the HOMO $\rightarrow L U M O+1$ transition. This data led to an estimate of the HOMO-LUMO gap of 1.9 and $1.92 \mathrm{eV}$ for THPP and TCPP, respectively. According to DFT calculations, the difference between the HOMO and LUMO energies is 2.66 and $2.70 \mathrm{eV}$, which is in perfect agreement with the electrochemical data. The electrochemically evaluated HOMO-LUMO gap (the difference between the oxidation and reduction potentials) amounted to 1.6 and $1.7 \mathrm{eV}$. The discrepancy between the spectroscopic and the calculated band-gap originates from the electron-hole pair binding energy [50] and large reorganization energy [51].

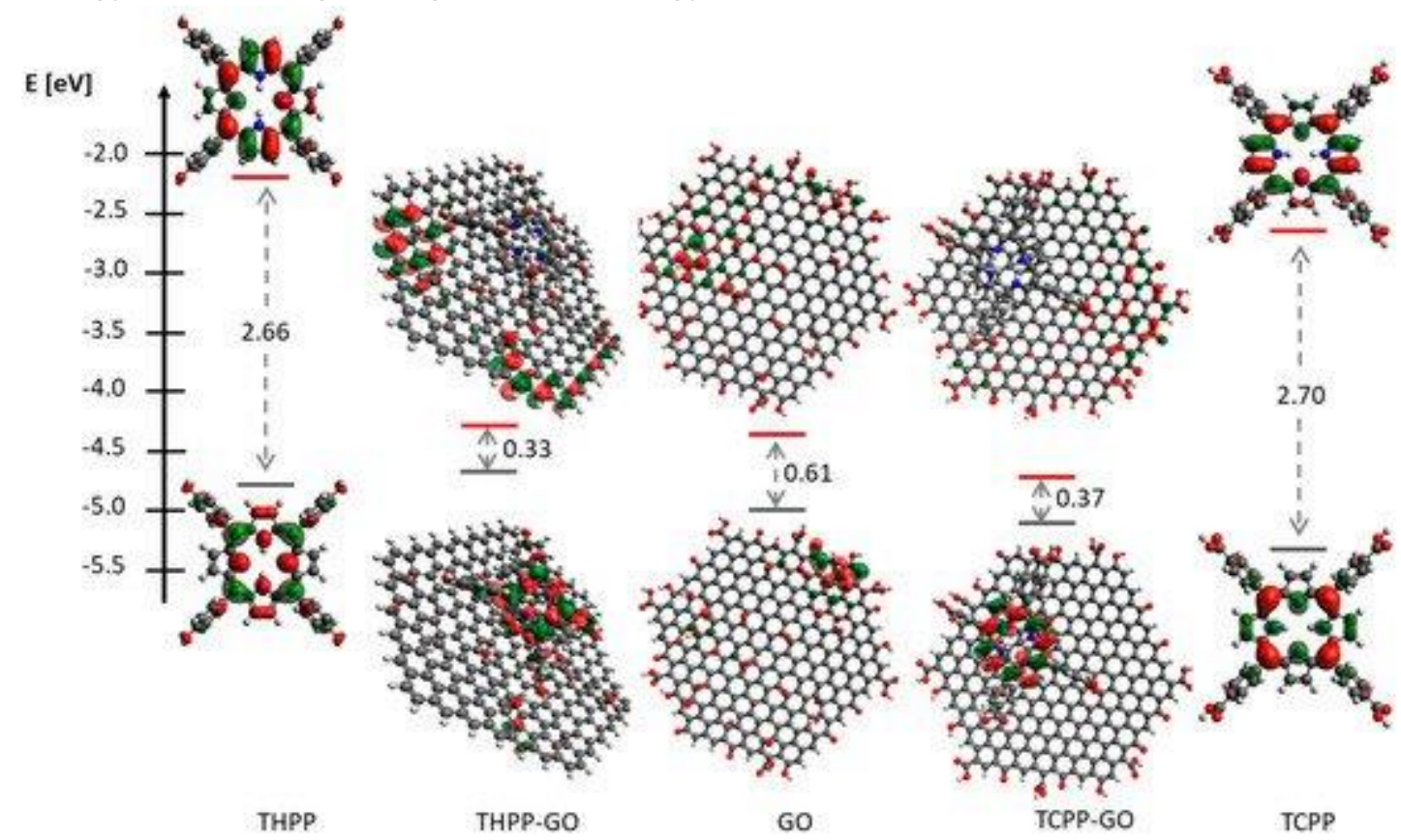

Figure 4. The energies of HOMO and LUMO orbitals of graphene oxide, studied porphyrins and their supramolecular assembly. Geometry of all these structures has been optimized at b3lyp/3-21 g level of theory.

Other quantum chemical parameters were computed to have more insights into the reactivity and selectivity of the porphyrins. The molecular orbital energies (i.e., Еномо and $E_{\text {LUMO) }}$ can provide information about the reactivity of chemical species and are often associated with the electron donating ability of a molecule [52,53,54]. The higher

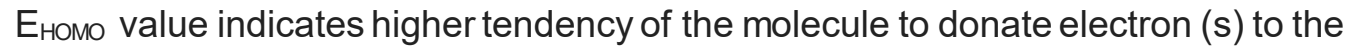
appropriate acceptor species with low energy and empty/partially filled atomic/molecular 
orbitals. The results obtained by DFT calculations and experimental measurements show that THPP has the higher value of $\mathrm{E}_{\text {номо }}$ than TCPP (see Figure 4). This effect is caused by different substituents at terminal aryl groups. It is well established, that in such systems the $-\mathrm{OH}$ group is an electron donor and $-\mathrm{COOH}$ group is an electron acceptor. Therefore, the THPP derivative has a higher tendency to donate electrons than TCPP, which may have significant electron acceptor character.

The energy levels of the GO structure were calculated and the corresponding electronic orbitals are presented in Figure 4. The calculated HOMO-LUMO band gap of $\mathrm{GO}$ is about $0.61 \mathrm{eV}$. This value corresponds to absorption bands in NIR/MIR IR range, and strongly heterogeneous atomic and electronic structures of $\mathrm{GO}$ indicate that fluorescence of $\mathrm{GO}$ arises from recombination of electron-hole pairs in localized electronic states originating from various possible configurations, rather than from band-edge transitions as is the case of typical semiconductors.

Due to GO cluster size the values of the energy gap are quite small. As published by Lonfat et al. the HOMO-LUMO energy gap decreases with the increase of the system size [55]. Molecular orbitals (HOMO and LUMO) and electron density are very useful for predicting the most reactive position in $\pi-$-electron systems and also explain several types of reaction in conjugated systems. The conjugated molecules are characterized by small HOMO, LUMO seperation, which is the result of a significant degree of charge transfer from end-capping electron-donor groups to the efficient electron acceptor groups through $\pi-$ conjugated path. In the THPP-GO and TCPP-GO complexes the energy gap is $0.33 \mathrm{eV}$ and $0.37 \mathrm{eV}$, respectively, and is eight times smaller than energy gap of free-metal porphyrins and smaller than the $\mathrm{GO}$ as well. The absence of any substantial red-shifted absorptions spectrum for porphyrin in the porphyrin-GO complex indicates that its HOMOLUMO transition is essentially unaffected by the formation of supramolecular hybrids with graphene oxide, which is also confirmed by DFT calculations [56].

\subsection{Vibrational Spectroscopy}

In order to interpret the experimental results of IR absorption and Raman scattering investigations into the quantum chemical calculations were performed and the DFT-level calculations of normal mode frequencies and intensities were performed. In Figure 5 the experimental and calculated infrared (Figure 5a,b) and Raman (Figure 5c,d) spectra of THPP, GO and THPP-GO and TCPP, GO, and TCPP-GO are presented respectively. The most important bands are also collated in Table 1 and Table 2. In general, conformity between the calculated and experimental spectra is quite good. The wavenumber shifts between them are typical and arise from approximations used in the computational procedure. Mainly the anharmonicity of vibrations and environment of the molecules which are neglected in our calculations cause those shifts. Panels in Figure 5show only selected spectral ranges where the differences between the spectra of both molecules are presented. 


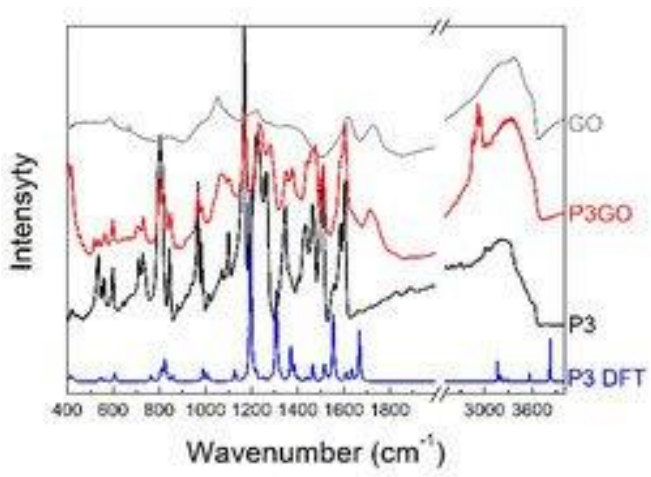

(a)

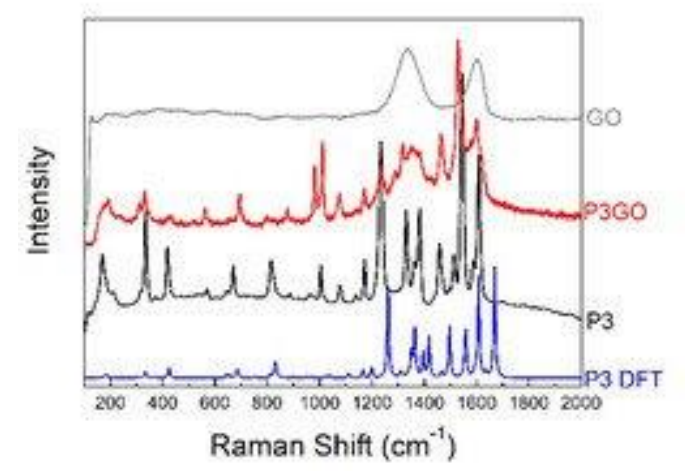

(c)

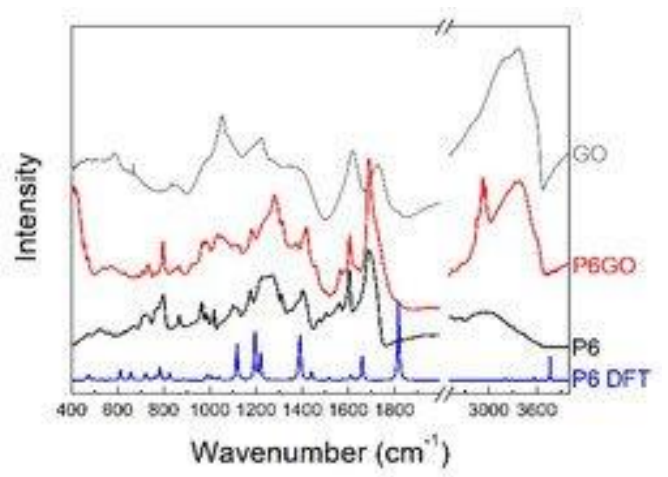

(b)

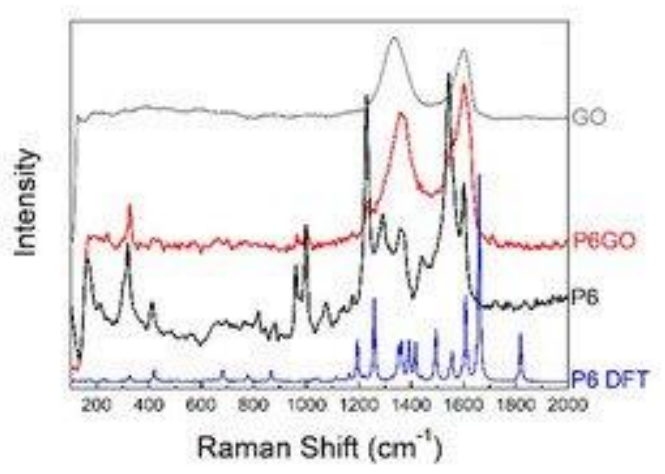

(d)

Figure 5. The calculated (blue) and experimental IR absorption (a,b) and Raman scattering (c,d) spectra of two metal-free porphyrins THPP and TCPP (black) and the experimental spectra of GO (gray) and hybrids THPP-GO and TCPP-GO (red) spectra at room temperature.

Table 1. Selected characteristic vibrational features of THPP and THPP-GO: $s$-stretching, b—bending, w-wagging, r-rocking, def.-deformation.

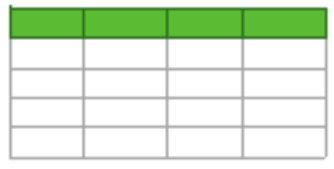

Table 2. Selected characteristic vibrational features of TCPP and TCPP-GO: $s$-stretching, b-bending, w-wagging, r-rocking, def.-deformation.

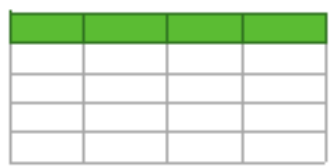

For the THPP in IR absorption spectrum at low frequencies the bands are located at $535,560,597,729,804$, and $983 \mathrm{~cm}^{-1}$ (Table 1). The first three bands are related to the wagging vibration of the $\mathrm{C}-\mathrm{H}$ bonds at the benzene rings and deformation of the porphyrin ring. The next three bands are observed for both porphyrins and are associated with wagging vibration of the $\mathrm{N}-\mathrm{H}$ bonds. They have also additional components related to the breathing of the pyrrole ring in the porphyrin ring. In the IR absorption spectra there are observed quite strong bands related to the stretching 
vibration of the $\mathrm{C}-\mathrm{C}$ and $\mathrm{C}=\mathrm{C}$ bonds in the porphyrin and benzene rings. They are located at 1465, 1508, 1586, and $1605 \mathrm{~cm}^{-1}$ for THPP, and at 1473, 1505, 1564, and 1605 $\mathrm{cm}^{-1}$ for TCPP (Table 2). For both samples the bands at about $1230 \mathrm{~cm}^{-1}$ corresponding to the stretching vibration of the $\mathrm{C}-\mathrm{C}$ bond between the porphyrin ring and aryl groups are also visible. This band is also good visible in the Raman scattering spectra and is located at $1234 \mathrm{~cm}^{-1}$ for THPP, and at $1231 \mathrm{~cm}^{-1}$ for TCPP. At the $1381 / 1358 \mathrm{~cm}^{-1}, 1459 / 1440$ $\mathrm{cm}^{-1}, 1516 / 1495 \mathrm{~cm}^{-1}$ and $1544 / 1545 \mathrm{~cm}^{-1}$, and $1608 / 1605 \mathrm{~cm}^{-1}$ observed for THPP/TCPP, respectively are located the bands related mainly to the stretching vibration of the $\mathrm{C}-\mathrm{C}, \mathrm{C}=\mathrm{C}$ and $\mathrm{C}-\mathrm{N}$ bonds, rocking vibration of the $\mathrm{C}-\mathrm{H}$ and $\mathrm{N}-\mathrm{H}$ bonds (see Table 1 and Table 2). In the range of $200-400 \mathrm{~cm}^{-1}$ the Raman scattering spectra of both porphyrins are similar. For example at this frequencies the bands are observed at $334 / 319$ and $417 / 410 \mathrm{~cm}^{-1}$ related to breathing of the porphyrin ring and deformation of the benzene rings, respectively. We cannot forget that the nature of the spectrum in this range are also affected by lattice vibrations.

Two different aryl groups linked to the porphyrin have an influence on IR and Raman spectra. In the IR absorption spectra for THPP there are observed quite strong bands at $1169 \mathrm{~cm}^{-1}$ and $1263 \mathrm{~cm}^{-1}$ associated with the bending vibration of the $\mathrm{C}-\mathrm{O}-\mathrm{H}$ and stretching vibration of the $\mathrm{C}-\mathrm{O}$ bonds. In Raman scattering spectra at $1171 \mathrm{~cm}^{-1}$ the band related to the bending vibration of the $\mathrm{C}-\mathrm{O}-\mathrm{C}$ bonds in the hydroxyl group is located. For TCPP the very strong band at $1691 \mathrm{~cm}^{-1}$ corresponds to the stretching vibration of the $\mathrm{C}=\mathrm{O}$ bond in the carboxyl group. Besides that some of the bands have additional components, for example the bands at 1176 and $1220 \mathrm{~cm}^{-1}$ are related to the bending vibration of the $\mathrm{C}-\mathrm{O}-\mathrm{H}$ bonds too. This and the other vibration in the aryl groups have influence on position and shape of bands related to the vibration in the porphyrin ring. The bands related to stretching vibration of $\mathrm{C}-\mathrm{H}$ and $\mathrm{O}-\mathrm{H}$ bonds located above $3000 \mathrm{~cm}^{-1}$ are less intense than the interaction between porphyrin molecules suggests.

FTIR spectroscopy is recognized as an important tool for the characterization of functional groups and in the case of GO has supported the presence of hydroxyl groups. The bands at: $1056,1223,1380,1616$, and $1727 \mathrm{~cm}^{-1}$ are related to the stretching vibration of the $\mathrm{C}-\mathrm{O}, \mathrm{C}-\mathrm{O}-\mathrm{C}, \mathrm{C}-\mathrm{OH}$, and $\mathrm{C}=\mathrm{O}$, respectively. Broad peak at $3000-3500 \mathrm{~cm}^{-1}$ is corresponding to the stretching vibration of the $\mathrm{C}-\mathrm{H}$ and $\mathrm{O}-\mathrm{H}[15,57]$.

The Raman spectrum of GO displays a D band at $\sim 1334 \mathrm{~cm}^{-1}$ and a broad G-band at $\sim 1603 \mathrm{~cm}^{-1}$. Thus, the integrated intensity ratio of the $D$ - and $G$-bands (ID/IG) indicates the oxidation degree and the size of $\mathrm{sp}^{2}$ ring clusters in a network of $\mathrm{sp}^{3}$ and $\mathrm{sp}^{2}$ bonded carbon. When porphyrin was assembled with $\mathrm{GO}, \mathrm{ID} / \mathrm{IG}$ decreased from 1.16 to 0.96 and 0.94 for THPP-GO and TCPP-GO, respectively. This fact indicates that the extended $\pi-$ electron structure on the surface of $\mathrm{GO}$ is formed on interactions with porphyrin molecules. Therefore it can be concluded that porphyrin molecules are assembled on GO through $\pi-$ $\pi$ stacking interactions $[58,59]$.

The IR absorption spectra of the THPP-GO and TCPP-GO (Figure 5) exhibit characteristic bands for the porphyrins, but the maxima of the bands are shifted (see Table 1 and Table 2) and their shape and relative intensity are different. The biggest changes are observed for the range between $1050-1700 \mathrm{~cm}^{-1}$. Within this range one can observe mostly bands related to: deformation vibration of the $\mathrm{C}-\mathrm{H}$ and $\mathrm{N}-\mathrm{H}$ bonds in the porphyrins 
rings, bending vibration, stretching vibration of the $\mathrm{C}-\mathrm{C}, \mathrm{C}-\mathrm{N}$, and $\mathrm{C}=\mathrm{C} \mathrm{C}=\mathrm{O}$ bonds in porphyrins and finally the bending vibration of the $\mathrm{C}-\mathrm{O}-\mathrm{H}$ bonds in aryl groups in both porphyrins. The big shifts are observed to the bands related to the stretching vibration of the $\mathrm{C}-\mathrm{C}$ and $\mathrm{C}=\mathrm{C}$ bonds in porphyrins rings. For THPP-GO these bands are located at 1442,1477 , and $1511 \mathrm{~cm}^{-1}$, and for TCPP-GO at 1418, 1470, and $1567 \mathrm{~cm}^{-1}$. On the lower frequencies bands associated to the deformation of the $\mathrm{C}-\mathrm{H}$ and $\mathrm{N}-\mathrm{H}$ bonds are located and changes in the band maximum position and intensity of the bands are visible. These changes may stem from the stiffening porphyrin molecule located above the plane of the graphene oxide. The most characteristic changes for the THPP are visible at the band 1223 $\mathrm{cm}^{-1}$ that is shifted in the THPP-GO hybrid to the $1233 \mathrm{~cm}^{-1}$ and is related to the bending vibration of the $\mathrm{C}-\mathrm{O}-\mathrm{H}$ bond. The other bands that have additional components associated with the vibration of the C-O-H bond are also shifted, for example 1346, and $1433 \mathrm{~cm}^{-1}$. The same changes are observed for the TCPP-GO. In this case the bands related to this vibration are located at 1176, 1221, and $1270 \mathrm{~cm}^{-1}$ for TCPP and at 1181, 1225, and 1279 $\mathrm{cm}^{-1}$ for TCPP-GO, respectively. For THPP-GO hybrid the bands related to the stretching vibration of the C-O bond in the aryl group is shifted about $18 \mathrm{~cm}^{-1}$ in comparison with THPP and is located at $1281 \mathrm{~cm}^{-1}$. For THPP-GO we also observe a new and quite strong band at $1377 \mathrm{~cm}^{-1}$, which is probably related to the deformation vibration of the $\mathrm{C}-\mathrm{H}$ bonds.

In the hybrid structures we also observe the changes in the characteristic bands for $\mathrm{GO}$. The band associated with the stretching vibration of the $\mathrm{C}-\mathrm{O}$ and $\mathrm{C}-\mathrm{O}-\mathrm{C}$ bonds located at 1056,1380 , and $1616 \mathrm{~cm}^{-1}$ in the hybrid almost disappeared. This suggests the formation of a covalent bond between the porphyrin and the graphene oxide via carboxyl and hydroxyl groups [58]. On the other hand, the bands related to the stretching vibration of the $\mathrm{C}=\mathrm{O}$ bonds at $1727 \mathrm{~cm}^{-1}$ are shifted to $1714 \mathrm{~cm}^{-1}$ and $1720 \mathrm{~cm}^{-1}$ when THPP and TCPP assemble with GO.

In the range above $3000 \mathrm{~cm}^{-1}$ there are located the bands related to the stretching vibration of the $\mathrm{C}-\mathrm{H}$ and $\mathrm{O}-\mathrm{H}$ bonds one can observe also very significant changes. In hybrid structures the bands are more exposed and separated. The band associated with $\mathrm{O}-\mathrm{H}$ vibration is strongly shifted even about $58 \mathrm{~cm}^{-1}$ in THPP-GO and is observed at 3312 and $3379 \mathrm{~cm}^{-1}$ in THPP-GO and TCPP-GO, respectively. In the spectrum of THPP-GO and TCPP-GO, the peak at $2924 / 2916 \mathrm{~cm}-1$ spons to the sp3 C-H characteristic stretching band. These results clearly indicate that the THPP and TCPP molecules have been noncovalently bonded to the graphene oxide by $\pi-\pi$ stacking and are not engaged in any other (e.g., hydrogen bonding) interaction.

As mentioned for GO two strong bands at 1334 (D) and $1603 \mathrm{~cm}^{-1}(\mathrm{G})$ [59] are observed. For the THPP-GO in the range of $1300-1600 \mathrm{~cm}^{-1}$ there are observed broader ranges corresponding to the pure GO. For the spectrum of THPP-GO are observed almost all characteristic bands for THPP too. The intensity of bands at 417 and 814 $\mathrm{cm}^{-1}$ decreases. This band corresponds to the deformation of the benzene ring and the bending vibration of the $\mathrm{C}-\mathrm{C}-\mathrm{C}$ bonds in porphyrins rings and wagging vibration of $\mathrm{N}-\mathrm{H}$ bonds, and the small stretching vibration of the $\mathrm{C}-\mathrm{O}$ bond in the aryl group. Other bands are shifted about $1-22 \mathrm{~cm}^{-1}$. The Raman scattering spectrum of the TCPP-GO hybrid system does not contain many distinct bands coming from pure porphyrin and is dominated by the two bands of graphene oxide. While the position of the G-band is the same, the D- 
band is shifted to $1363 \mathrm{~cm}^{-1}$ for the TCPP-GO complex. The same bands derived from pure porphyrins have a low intensity. For example the bands related to the breathing of the porphyrin ring of TCPP are located at 319 and $999 \mathrm{~cm}^{-1}$ and in the TCPP-GO they are shifted to 324 and $1003 \mathrm{~cm}^{-1}$. The band corresponding to the wagging vibration of the $\mathrm{N}-$ $\mathrm{H}$ bond of TCPP is at $671 \mathrm{~cm}^{-1}$ and of TCPP-GO is shifted to position $690 \mathrm{~cm}^{-1}$. The strong band registered to porphyrin at $1231 \mathrm{~cm}^{-1}$ and corresponding to the stretching vibration of the $\mathrm{C}-\mathrm{C}$ bond between the porphyrin ring and aryl substituent is shifted to $1236 \mathrm{~cm}^{-1}$ and almost invisible. The similar changes are also observed for the band at 1545 $\mathrm{cm}^{-1}$ associated with the stretching vibration of $\mathrm{C}=\mathrm{C}$ bonds in the porphyrin ring. These results obtained from FTIR indicate the bonds formation between the porphyrins and GO structures. These hybrids are formed by the hydroxyl and carboxyl groups.

On the other hand, when porphyrin was assembled with $G O, I D / I G$ decreased from 1.16 to $0.96,0.94$ for THPP-GO and TCPP-GO, respectively. This indicates that the big $\pi-$ electron structure on the surface of $\mathrm{GO}$ was formed. Thus, porphyrins could be assembled on $G O$ through $\pi-\pi$ stacking interaction $[60,61]$. The $D / G$ intensity ratio of hybrids decreases, indicating that the graphene carbons of the composites contain fewer defects than the GO. The decreasing ID/IG ratio corresponding to the presence of $G O$ domains $\mathrm{sp}^{2}$ hybridized too. Lomeda et al. [62] reported that the decreased ID/IG ratio is a result of the functionalization of GO. In addition, the hybrid shows a shift of the D peak towards higher wave-numbers, which confirms the ordered porphyrin-GO assembly.

The changes in vibrational spectra suggested some possible electron transfer processes, which potentially could lead to the reduction of graphene oxide with the THPP. In order to verify this hypothesis a set of EPR spectra of GO and GO complexes with two studied porphyrins have been recorded within a large temperature range (20-300 K).

\subsection{Magnetism}

As it was shown in ultrasonic irradiation and some reagents can create additional hydroxyl radicals in solution, which should affect the magnetic properties of the final material. Therefore, using EPR we studied both GO obtained from water or water/THF mixtures. Figure 6 presents EPR spectra of powdered GO samples obtained after evaporation of sonificated $\mathrm{GO}$ from $\mathrm{H}_{2} \mathrm{O}$ or $\mathrm{H}_{2} \mathrm{O}$ \& THF solutions. At $300 \mathrm{~K}$ the spectra consist of an almost symmetrical, strong Lorentzian line (linewidth $\Delta \mathrm{B}_{\mathrm{pp}}=1.30 \pm 0.05 \mathrm{Gs}$ ) with g-factor $2.0029 \pm 0.0002$, similarly as previously observed $[63,64]$. The difference in line intensity for both samples (see the gain of the amplifier on Figure 6) indicates that THF used in solution has some impact on the number and/or type of paramagnetic centers in $\mathrm{GO}$, which may be associated with different unfolding/deaggregation in different solvent systems. For both samples, especially at low temperature, one can observe weak satellite lines resulting from electron-proton interaction [65]. Temperature study of spin susceptibility $X$ EPR were performed to obtain information about the type of paramagnetic centers in the samples as presented in Figure 7. 


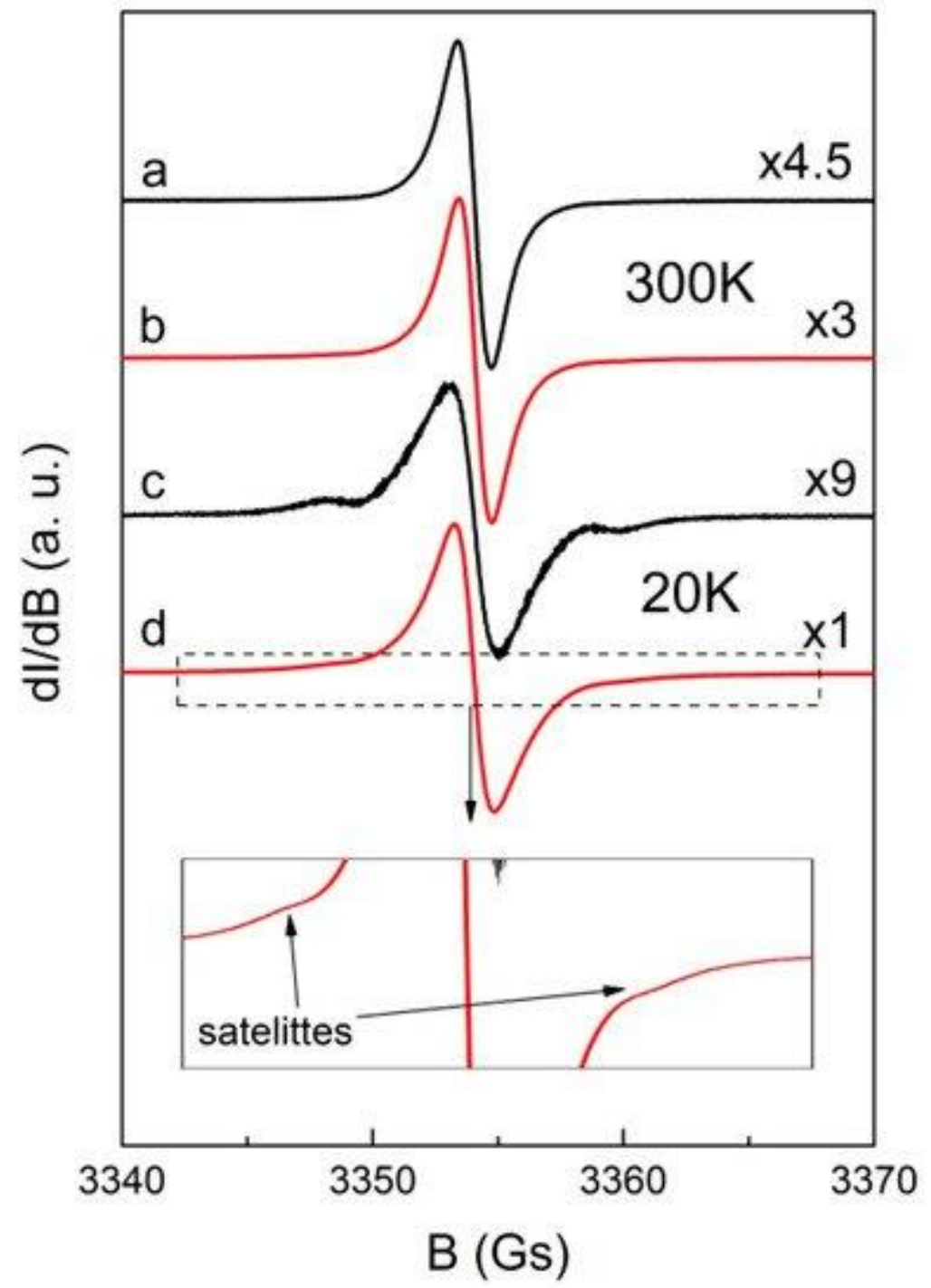

Figure 6. Electron paramagnetic resonance (EPR) spectra of powdered GO recorded at 300 and $20 \mathrm{~K}$ obtained after evaporation of sonificated $\mathrm{GO}$ from $\mathrm{H}_{2} \mathrm{O}(\mathbf{a}, \mathbf{c})$ and $\mathrm{GO}$ from $\mathrm{H}_{2} \mathrm{O}$ \&THF (b,d) solution. The numbers on the right side denote the relative amplifier gain and insert indicates the satellite lines. 


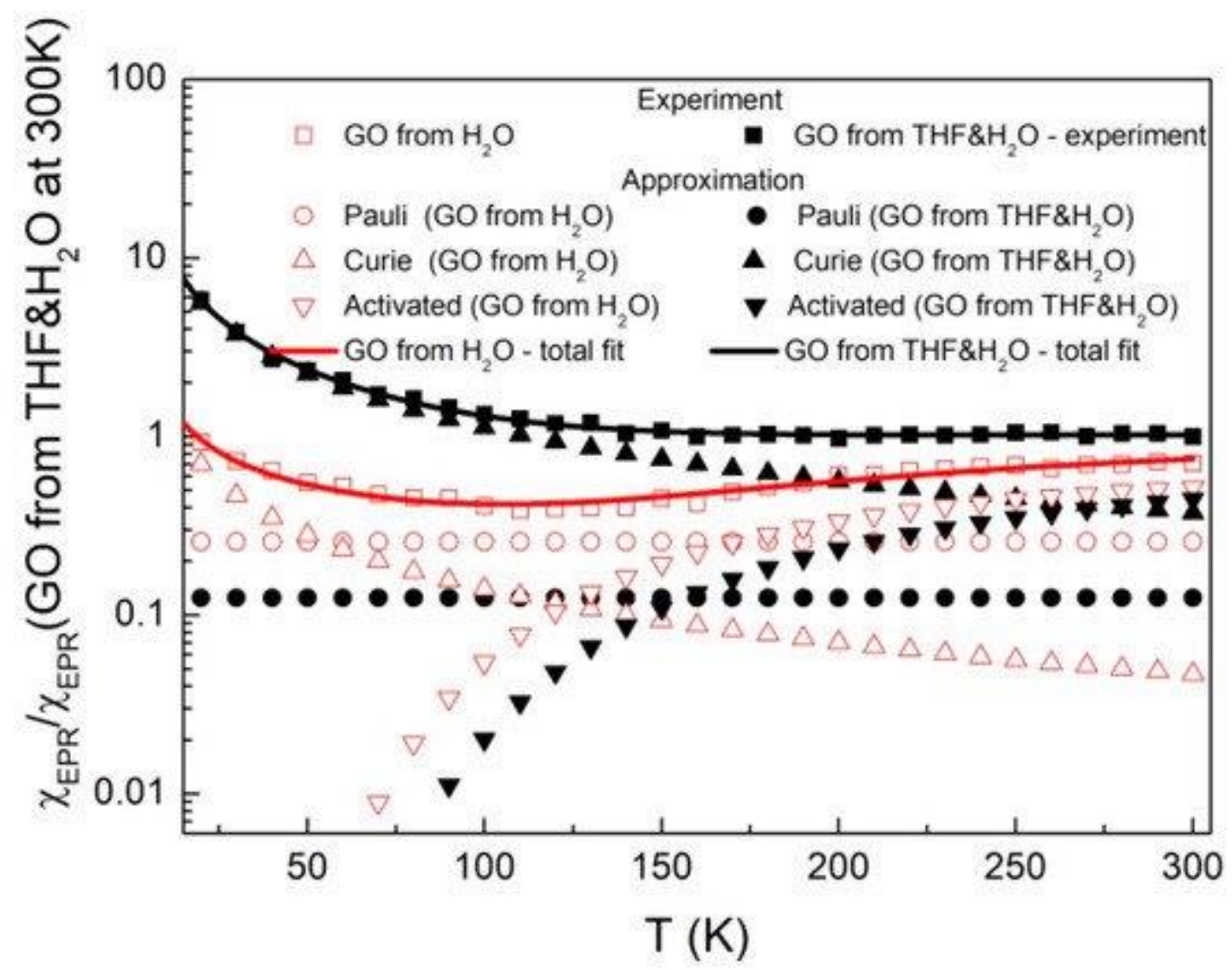

Figure 7. Spin susceptibility of powdered $\mathrm{GO}$ after evaporation of sonificated $\mathrm{GO}$ from $\mathrm{H}_{2} \mathrm{O}$ and $\mathrm{H}_{2} \mathrm{O}$ \&THF solution.

Experimental points of spin susceptibility (proportional to double integrated EPR signal), denoted in Figure 7 as squares, can by approximated by the following equation:

$$
X \operatorname{EPR}(\mathrm{T})=\mathrm{A}+\mathrm{C} 1 \mathrm{~T}+\mathrm{C} 2 \mathrm{Te}-\Delta \mathrm{EkBT}
$$

where $A$ is the constant, $T$ is the temperature, $C_{1}$ and $C_{2}$ are the Curie constants, $k_{\mathrm{B}}$ is the Boltzmann constant and $\Delta \mathrm{E}$ is the activation energy.

The first term in Equation (2) describes delocalized electrons (Pauli susceptibility), and the second and third ones describe localized paramagnetic centers for Curie and thermal activated spin susceptibility, respectively. The last part of spin susceptibility may result from antiferromagnetic coupled neighboring defects at low temperatures. Table 3 presents the parameters obtained from fit of Equation (2) to experimental data. Over the whole temperature range the total spin susceptibility is higher for the sample prepared from $\mathrm{H}_{2} \mathrm{O}$ \&THF solution. This is due to the strong oxidation processes that manifest as a rapid growth of the Curie component and decreasing of Pauli and activated spin susceptibility. Table 3. Parameters of spin susceptibility obtained from approximation of Equation (2) to experimental points.

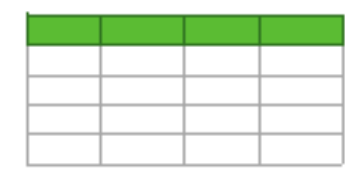

Figure 8 presents the EPR spectra of hybrid systems porphyrin-GO with g-factors 
$2.0028 \pm 0.0002$ and $2.0029 \pm 0.0002$ at $300 \mathrm{~K}$ for THPP-GO and TCPP-GO,

respectively. The linewidths of porphyrin-GO are only slightly broadened in comparison to GO: $\Delta \mathrm{B}_{\mathrm{pp}}=1.45 \pm 0.05$ for THPP-GO and $\Delta \mathrm{B}_{\mathrm{pp}}=1.42 \pm 0.05 \mathrm{Gs}$ for TCPP-GO. The spectra of hybrid samples are not a superposition of $\mathrm{GO}$ and porphyrins indicate strong interactions between the components.

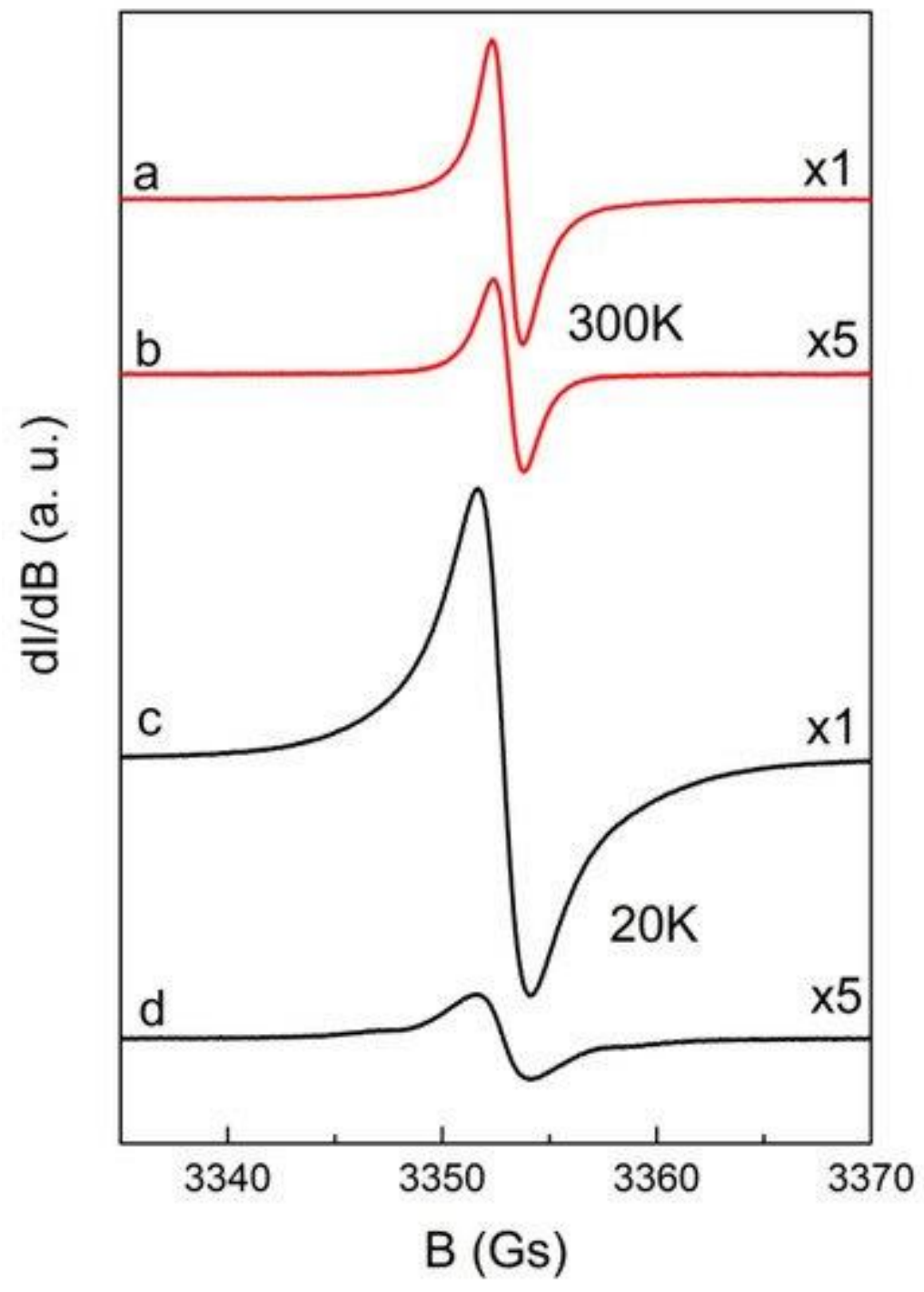

Figure 8. EPR spectra of THPP-GO from $\mathrm{H}_{2} \mathrm{O}$ \&THF $(\mathbf{a}, \mathbf{c})$ and TCPP-GO from $\mathrm{H}_{2} \mathrm{O}$ \& THF $($ b,d) recorded at 20 and $300 \mathrm{~K}$. The numbers on the right side denote the relative amplifier gain.

The mutual influence of $\mathrm{GO}$ and porphyrins on electronic properties can be tracked by comparison of spin susceptibility versus temperature. As shown in Figure 9, Equation (2) with parameters presented in Table 3describes satisfactorily all experimental data. Spin susceptibility of hybrid samples, similar as in the case of EPR spectra, is not a superposition of GO and porphyrins. For TCPP-GO hybrid sample, there is a noticeable decrease of susceptibility in comparison with pure $\mathrm{GO}$ from $\mathrm{H}_{2} \mathrm{O}$ \&THF. In our case this reduction does not exceed experimental error if one compares Pauli part of the spin concentration of TCPP-GO $\left(0.37 \pm 0.02 \times 10^{17}\right.$ electrons $\left./ g\right)$ with $\mathrm{GO}$ from $\mathrm{H}_{2} \mathrm{O}$ \&THF $(0.45$ $\pm 0.17 \times 10^{17}$ electrons $\left./ g\right)$. 


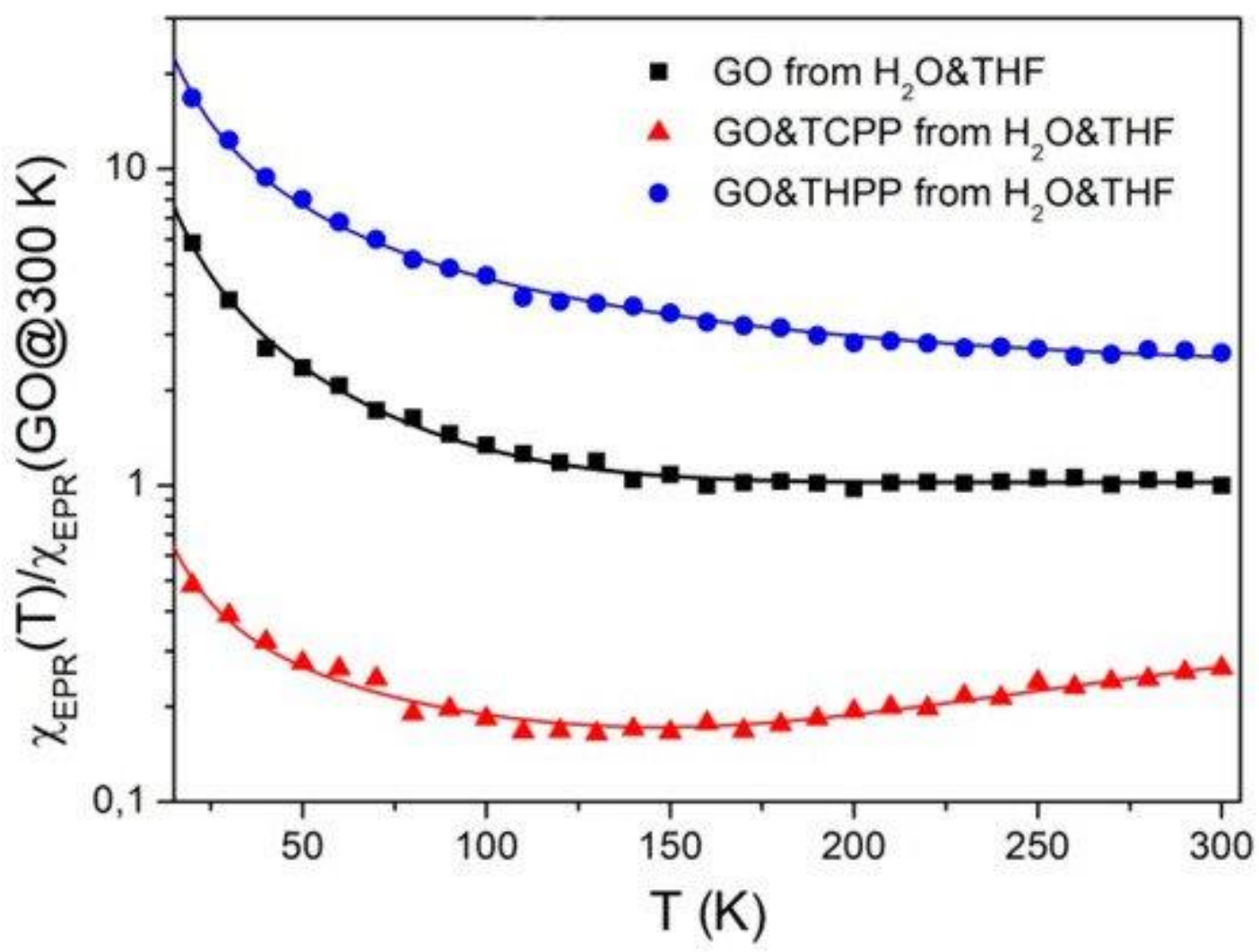

Figure 9. Comparison of the relative spin susceptibility of $\mathrm{GO}$, porphyrin and hybrid system of THPP-GO and TCPP-GO. Symbols indicate experimental points and lines are fits according to Equation (2).

A different behaviour of spin susceptibility to those described for TCPP-GO shows a THPP-GO hybrid. One can observe a significant increase of spin susceptibility (Figure 9) in the whole temperature range in comparison with $\mathrm{GO}$ from $\mathrm{H}_{2} \mathrm{O}$ \&THF. This phenomenon is especially visible for Pauli part for which the spin concentration (4.58 \pm $0.24 \times 10^{17}$ electrons $/ g$ ) exceeds one order of magnitude in comparison with $\mathrm{GO}$ from $\mathrm{H}_{2} \mathrm{O}$ \&THF (see Table 3). Such an increase in the number of delocalized electrons of THPP-GO indicates on expanding of $\pi$ structure due to the assembling of THPP on GO through $\pi-\pi$ stacking interaction.

This striking magnetic behaviour of graphene oxide and its supramolecular assemblies with porphyrins can be explained on the basis of DFT calculations under open shell conditions. It is a well-known fact that higher acenes as well as other large aromatic conjugated systems show significant radical character despite even number of valence electrons. Due to magnetic effects large aromatic systems become di- or even polyradicals, however in total the bear singlet configuration and the electrons are usually antiferromagnetically coupled $[66,67]$. This effect is, among others, responsible for very low stability of pentacene and higher acenes, graphene folding and other phenomena, but also gives rise to prospective applications of carbon-based materials in spintronics [68]. In the case of graphene oxide, however, some reports predict ferromagnetic coupling of electrons belonging to the edges of aromatic domains. Various carbon nanomaterials are expected to be magnetic [69]. Graphene oxide, especially containing epoxy groups, is also expected to be magnetic with significant ferromagnetic coupling $[70,71,72,73]$. 
Furthermore, these magnetic properties are much more evident in the case of reduced graphene oxide $[74,75]$ and the measurements of magnetic properties of graphene oxide were reported as a useful tool for monitoring the reduction process $[73,76]$.

DFT calculations of studied systems indicate significant spin impurities within pristine graphene oxide (Figure 10b), its TCPP complex (Figure 10a), and the THPP-GO complex (Figure 10c).
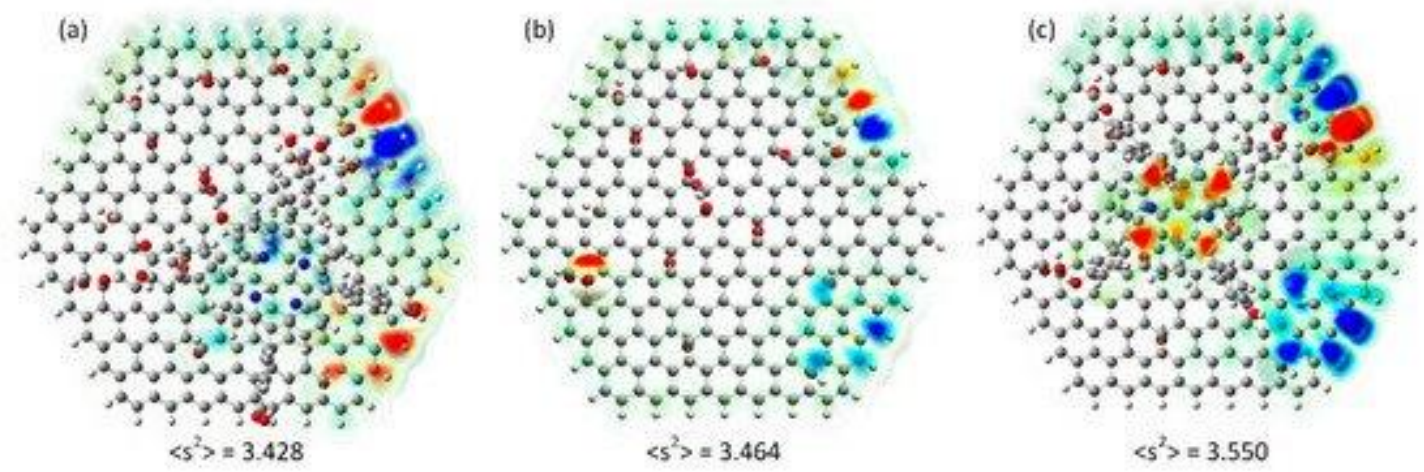

Figure 10. Computed spin density projected in the charge density isosurface for the TCPPGO complex (a), pristine graphene oxide (b) and the THPP-GO complex (c). Number on figures indicate calculated values for the sum of squared spin densities of individual atoms. Red areas correspond to spin $\alpha$ and blue ones to spin $\beta$.

These results are fully consistent with observed magnetic properties. In clearly indicated the role of electron donor and electron acceptor substituents in porphyrin rings on magnetic properties of graphene oxide. It is evident that even a subtle change results in a very significant change. Moreover, stronger $\pi$ electron interaction (as in the case of THPP) results in the partial delocalization of unpaired electrons over the porphyrin ring as shown in Figure 10c. These theoretical results do not reproduce the experimental data quantitatively, but support qualitatively the observed trends. It is caused by the low level of applied theory (due to the size of the molecule other methods are demand much higher computing power). Therefore one can conclude that observed magnetic behavior, i.e., increased spin susceptibility in the case of THPP and decreased in the case of TCPP are fully consistent with simple computational model.

\section{Materials and Methods}

\subsection{Materials}

The 5,10,15,20-Tetrakis (4-hydroxyphenyl)-21H,23H-porphine (THPP), and 5,10,15,20-Tetrakis(4-carboxyphenyl) 21H,23H-porphine (TCPP) were purchased from Sigma-Aldrich (Poznań, Poland). Their molecular structures are presented in Figure 11. 


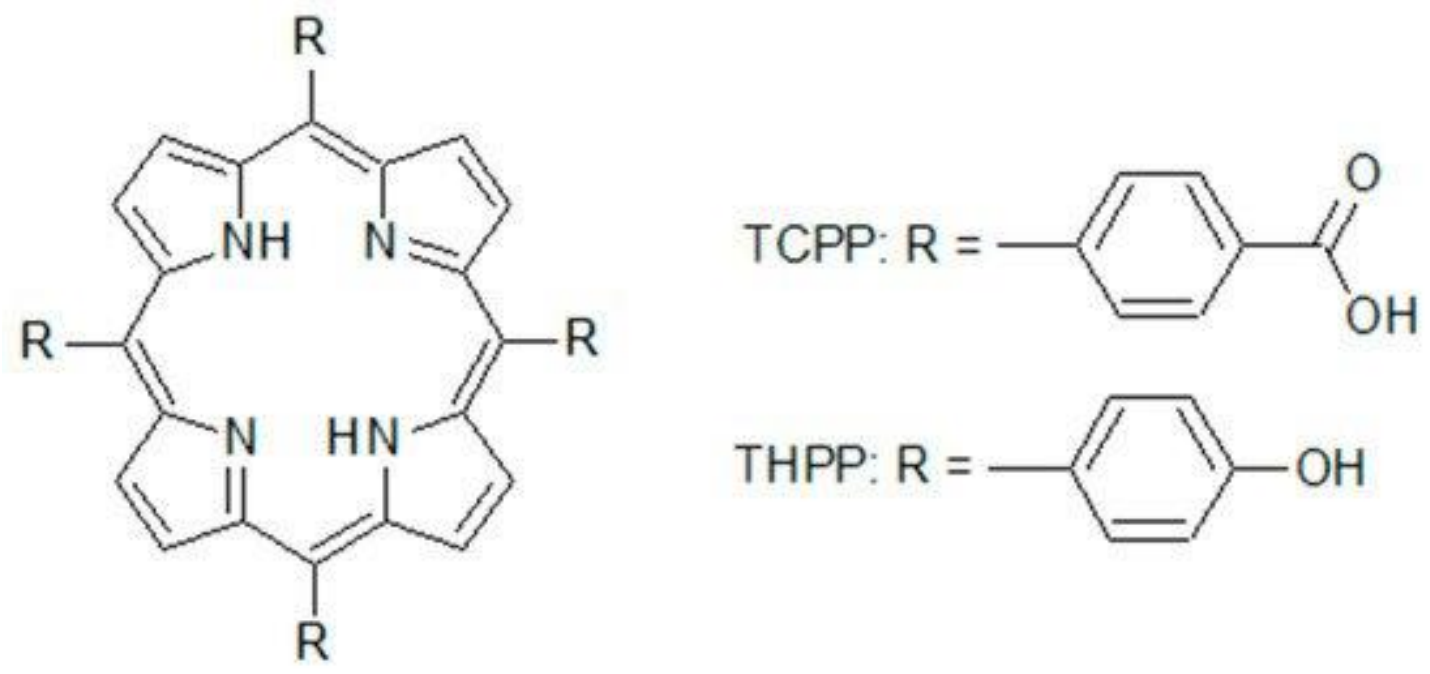

Figure 11. The molecular structures of THPP and TCPP.

Graphene oxide was synthesized from natural graphite powder by the modified Hummers method. Graphite powder $(3 \mathrm{~g})$ and $\mathrm{KNO}_{3}(3 \mathrm{~g})$ were added to concentrated $\mathrm{H}_{2} \mathrm{SO}_{4}(90 \mathrm{~mL})$ and the mixture was stirred in ice bath. Small portions of the oxidizing agent $\mathrm{KMnO}_{4}(9 \mathrm{~g})$ were added slowly in order to keep the suspension temperature below $2{ }^{\circ} \mathrm{C}$. The reaction mixture was maintained at approx. $0^{\circ} \mathrm{C}$ and it was vigorously stirred for $15 \mathrm{~min}$ resulting in the increase of temperature to $35^{\circ} \mathrm{C}$. The stirring was continued for $7 \mathrm{~h}$. Afterwards, $90 \mathrm{~mL}$ of distilled water was slowly added and the mixture temperature increased to $80^{\circ} \mathrm{C}$. After $15 \mathrm{~min}$ the suspension was cooled to room temperature and the reaction was quenched by the addition of $12 \mathrm{~mL}$ of $\mathrm{H}_{2} \mathrm{O}_{2}(30 \%)$. In the first step of the purification process the diluted (with $250 \mathrm{~mL}$ of distilled water) supernatant was poured off. The precipitant was rinsed two times with $250 \mathrm{~mL}$ of distilled water and the supernatant was removed. Then the product was centrifuged in 1 $\mathrm{mol} / \mathrm{dm}^{3} \mathrm{HCl}$ aqueous solution at $6000 \mathrm{rpm}$ for $3 \mathrm{~min}$ three times (to remove manganese compounds) followed by decantation. Afterwards, the process was repeated four times with distilled water. The final product was dried at room temperature.

For THPP-GO, TCPP-GO composites, we have synthesized distilled water $\left(\mathrm{H}_{2} \mathrm{O}\right)$ soluble graphene oxide. Briefly, $4 \mathrm{mg}$ of as prepared graphene oxide (GO) was dissolved in $20 \mathrm{~mL} \mathrm{H} \mathrm{H}_{2} \mathrm{O}$ under mild ultrasonication until brown solution appeared.

The solutions of porphyrins modifiers were prepared by the dissolution of porphyrin in $50 \mathrm{~mL}$ THF to achieve a concentration of $10^{-5} \mathrm{M}$. In the next step $0.2 \mathrm{~mL}$ of the porphyrin solution were mixed with $\mathrm{GO}$ distilled water solution with increasing concentrations (from 0 to $1.64 \mu \mathrm{g} / \mathrm{mL}$, then sonicated for 15,30 , and $60 \mathrm{~min}$, thus yielding final products labelled THPP-GO and TCPP-GO, respectively.

\subsection{Instrumentation}

Diffuse reflectance spectra were measured on Lambda 750 (Perkin Elmer, Norwalk, CT, USA) spectrophotometer, sapmles were dispersed in spectrally pure barium sulfate prior to measurements, the same materials were used as reference samples. For the infrared spectroscopy, Raman scattering, and EPR spectroscopy measurements the complexes were prepared by the dissolution of porphyrin in $2.5 \mathrm{~mL}$ THF $\left(10^{-3} \mathrm{M}\right)$. In the 
next step 0.25 or $0.75 \mathrm{~mL}$ of the porphyrins solution were mixed (sonification) with $2.5 \mathrm{~mL}$ $\mathrm{GO}$ dissolved in $\mathrm{H}_{2} \mathrm{O}$. After evaporation of the solution, a hybrid material was obtained in the form of a powder. The infrared absorption spectra were recorded using an FTIR Bruker Equinox 55 spectrometer (Bruker Optics, Ettlingen, Germany) equipped with Bruker Hyperion 1000 microscope in the range $400-4500 \mathrm{~cm}^{-1}$ at room temperature. Raman scattering spectra of the investigated compounds were recorded using LabRAM HR 800 spectrophotometer (HORIBA Jobin Yvon, Montpellier, France) with excitation $\lambda_{\mathrm{exc}}=458 \mathrm{~nm}$. The power of the laser beam at the sample in all cases was less than $1 \mathrm{~mW}$ with a power density of about $3 \times 10^{8} \mathrm{~mW} \mathrm{~cm}^{-2}$. Such low power density was necessary to avoid decomposition of the sample. The infrared absorption and Raman scattering was measured from pure samples not dispersed in the matrix. EPR studies were performed using BRUKER ELEXSYS E500 spectrometer (Bruker, Billerica, MA, USA) in the temperature range 20-300 K. EPR spectrometer was equipped with Super High Sensitivity Probe head and ER 036TM NMR-Teslameter. Sample temperature was controlled in OXFORD ESR900 cryostat by ITC503S controller (Tubney Woods, Abingdon Oxfordshire, UK). Low microwave power $(0.6 \mathrm{~mW})$ was applied to avoid saturation effect.

\subsection{Computation}

In order to realize an optimal structure of the compounds and to interpret the experimental results of UV-Vis, IR absorption and Raman scattering investigations quantum chemical calculations were performed. The molecular geometries were optimized using the Density Functional Theory (DFT) method with B3LYP hybrid functional and 3$21 \mathrm{G}$ basis set. Due to large atom numbers and open shell calculations larger basis sets could not be used due to the limitations of our cluster. The calculations of normal mode frequencies and intensities were also performed. All calculations were made using a Gaussian 09 package (Wallingford, CT USA) [77]. The GaussView (Wallingford, CT USA, Version E01) [78] program was used to propose an initial geometry of investigated molecules and for visual inspection of the normal modes.

\section{Conclusions}

We successfully developed a simple and effective method for preparing porphyrinGO hybrids that have donor-acceptor properties and are characterized by the charge transfer between porphyrin and graphene oxide. Various spectroscopic studies indicate significant non-covalent interaction, which does not modify optical properties of porphyrin itself (except of significant photoluminescence quenching) but dramatically changes magnetic properties. This effect is attributed to subtle tuning of graphene domain magnetism induced by electron density modulation by electron donor or electron acceptor substituents.

Fluorescence quenching with increasing GO content shows electron transfer from the porphyrin molecule to $\mathrm{GO}$, and an additional band at $627 \mathrm{~nm}$ indicates the interaction between porphyrin and graphene oxide. The creation of a hybrid system can also be demonstrated by recorded IR absorption and Raman scattering spectra. The appearance of an additional band for example with a maximum at $1731 \mathrm{~cm}^{-1}$ associated with the oscillation of $\mathrm{C}=\mathrm{O}$ bonds and changes in the spectrum above $3000 \mathrm{~cm}^{-1}$ suggest the 
interactions between porphyrin and GO through the carboxyl and hydroxyl groups. We demonstrated the expanding of $\pi$ structure due to the assembling of porphyrin on $\mathrm{GO}$ through a $\pi-\pi$ stacking interaction too. The EPR spectroscopy showed that porphyrins have a significant influence on the electron properties of hybrid materials. This is particularly manifested for THPP in the part of Pauli's magnetic susceptibility describing delocalized electrons, which exerts a profound effect of the magnetic properties of the hybrid.

We believe that our facile method provides a simple and practical means of functionalization of graphene oxide and thus leads to the further development of a new class of GO based structures, finding various applications, especially in spintronics and optoelectronics.

\section{References}

1. Burrell, A. K.; Officer, D. L.; Reid, D. C. W., Aldehyde-appended tetraphenylporphyrin - a new building-block for porphyrin arrays. Angew Chem Int Edit 1995, 34, 900-902.

2. Liu, C. Y.; Bard, A. J., Addressing of optoelectronic memory of thin film zinc porphyrin with crossed 5 mu m indium tin oxide arrays. Electrochem Solid St 2001, 4, E39-E41.

3. Berlicka, A.; Pacholska, E.; Latos-Grazynski, L., 10,15-di(4-pyridyl)-5,20-di(4-tolyl)-21thiaporphyrin as a building block for porphyrin coordination arrays. J Porphyr Phthalocya 2003, 7, 8-16.

4. Yu, L. H.; Speckbacher, M.; Lindsey, J. S., Acid catalysis with mg- or zn-porphyrins yielding mixed-metal multiporphyrin arrays. Abstr Pap Am Chem S 2003, 225, U95-U95.

5. Sun, J. Z.; Yang, X. G.; Li, H. Y.; Huang, J.; Wang, M., An acid-base controlled fluorescence switch based on a free-base-porphyrin-perylene-diimide molecular array. Chem $J$ Chinese $U$ 2004, 25, 2148-2152.

6. Hajjaj, F.; Yoon, Z. S.; Yoon, M. C.; Park, J.; Satake, A.; Kim, D. H.; Kobuke, Y., Assemblies of supramolecular porphyrin dimers in pentagonal and hexagonal arrays exhibiting lightharvesting antenna function. J Am Chem Soc 2006, 128, 4612-4623.

7. Otsuki, J.; Kawaguchi, S.; Yamakawa, T.; Asakawa, M.; Miyake, K., Arrays of double-decker porphyrins on highly oriented pyrolytic graphite. Langmuir 2006, 22, 5708-5715.

8. Leng, X. B.; Choi, C. F.; Lo, P. C.; Ng, D. K. P., Assembling a mixed phthalocyanine-porphyrin array in aqueous media through host-guest interactions. Org Lett 2007, 9, 231-234.

9. Seidel, R. W.; Oppel, I. M., 1d and 2d solid-state metallosupramolecular arrays of freebase 5,10,15,20-tetra(4-pyridyl)porphyrin, peripherally linked by zinc and manganese ions. Struct Chem 2009, 20, 121-128. 
10. Seidel, R. W.; Oppel, I. M., 2d metallosupramolecular arrays of zinc-5,10,15,20-tetra(4pyridyl)porphyrin via self-complementary coordination and peripheral linkage. Z Anorg Allg Chem 2010, 636, 446-448.

11. Li, A.; Zhao, L. Z; Hao, J.; Ma, R. J.; An, Y. L.; Shi, L. Q., Aggregation behavior of the template-removed 5,10,15,20-tetrakis(4-sulfonatophenyl)porphyrin chiral array directed by poly(ethylene glycol)-block-poly(l-lysine). Langmuir 2014, 30, 4797-4805.

12. Han, C.; Shao, Q.; Liu, M.; Ge, S. S.; Liu, Q. Y.; Lei, J., 5,10,15,20-tetrakis(4chlorophenyl)porphyrin decorated tio2 nanotube arrays: Composite photoelectrodes for visible photocurrent generation and simultaneous degradation of organic pollutant. Mat Sci Semicon Proc 2016, 56, 166-173.

13. Ogawa, T., Analysis of single molecule conductance of heterogeneous porphyrin arrays by partial transmission probabilities. Chemistryselect 2017, 2, 7483-7483.

14. Tamaki, T.; Ohto, T.; Yamada, R.; Tada, H.; Ogawa, T., Analysis of single molecule conductance of heterogeneous porphyrin arrays by partial transmission probabilities. Chemistryselect 2017, 2, 7484-7488.

15. Wang, R. B.; Brugh, A. M.; Rawson, J.; Therien, M. J.; Forbes, M. D. E., Alkyne-bridged multi[copper(ii) porphyrin] structures: Nuances of orbital symmetry in long-range, through-bond mediated, isotropic spin exchange interactions. J Am Chem Soc 2017, 139, 9759-9762.

16. Zhou, H. C.; Baldini, L.; Hong, J.; Wilson, A. J.; Hamilton, A. D., Pattern recognition of proteins based on an array of functionalized porphyrins. J Am Chem Soc 2006, 128, 2421-2425.

17. Zhao, Q. D.; Yu, M.; Xie, T. F.; Peng, L. L.; Wang, P.; Wang, D. J., Photovoltaic properties of a zno nanorod array affected by ethanol and liquid-crystalline porphyrin. Nanotechnology 2008, 19.

18. Zhao, Z. X.; Cammidge, A. N.; Cook, M. J., Towards black chromophores: Mu-oxo linked phthalocyanine-porphyrin dyads and phthalocyanine-subphthalocyanine dyad and triad arrays. Chem Commun 2009, 7530-7532.

19. Pinkerton, N. M.; Gindy, M. E.; Calero-DdelC, V. L.; Wolfson, T.; Pagels, R. F.; Adler, D.; Gao, D. Y.; Li, S. K.; Wang, R. B.; Zevon, M.; Yao, N.; Pacheco, C.; Therien, M. J.; Rinaldi, C.; Sinko, P. J.; Prud'homme, R. K., Single-step assembly of multimodal imaging nanocarriers: Mri and long-wavelength fluorescence imaging. Adv Healthc Mater 2015, 4, 1376-1385.

20. Zhu, P. H.; Wang, P. P.; Kan, T. L.; Sun, G. Q.; Zhang, Y.; Yu, J. H., An enhanced photoelectrochemical immunosensing platform: Supramolecular donor-acceptor arrays by assembly of porphyrin and c-60. Biosens Bioelectron 2015, 68, 604-610. 
21. Bruce, R. C.; Wang, R. B.; Rawson, J.; Therien, M. J.; You, W., Valence band dependent charge transport in bulk molecular electronic devices incorporating highly conjugated multi[(porphinato)metal] oligomers. J Am Chem Soc 2016, 138, 2078-2081.

22. Davila, J.; Harriman, A.; Milgrom, L. R., A light-harvesting array of synthetic porphyrins. Chem Phys Lett 1987, 136, 427-430.

23. Batteas, J. D.; Harriman, A.; Kanda, Y.; Mataga, N.; Nowak, A. K., Photoinduced charge separation in a porphyrin tetraviologen supramolecular array. J Am Chem Soc 1990, 112, 126133.

24. Osuka, A.; Tanabe, N.; Zhang, R. P.; Maruyama, K., An efficient synthesis of linear porphyrin arrays. Chem Lett 1993, 1505-1508.

25. Anderson, S.; Anderson, H. L.; Bashall, A.; Mcpartlin, M.; Sanders, J. K. M., Assembly and crystal-structure of a photoactive array of 5 porphyrins. Angew Chem Int Edit 1995, 34, 10961099.

26. Chambron, J. C.; Dietrichbuchecker, C. O.; Heitz, V.; Nierengarten, J. F.; Sauvage, J. P.; Pascard, C.; Guilhem, J., Transition-metals as assembling and templating species - from catenanes and knots to organized multi-porphyrins arrays. Pure Appl Chem 1995, 67, 233-240.

27. Crossley, M. J.; Govenlock, L. J.; Prashar, J. K., Synthesis of porphyrin-2,3,12,13-tetraones and porphyrin-2,3,7,8-tetraones - building-blocks for the synthesis of extended porphyrin arrays. J Chem Soc Chem Comm 1995, 2379-2380.

28. Dinatale, C.; Brunink, J. A. J.; Bungaro, F.; Davide, F. A. M.; Damico, A.; Paolesse, R.; Boschi, T.; Faccio, M.; Ferri, G., Fish freshness determination with a metallo-porphyrins coated qmb sensor array. Sensors Ser 1995, 48-51.

29. Amabilino, D. B.; DietrichBuchecker, C. O.; Sauvage, J. P., Rings-and-string approach to the construction of porphyrin arrays by transition-metal-directed threading. J Am Chem Soc 1996, 118, 3285-3286.

30. Arai, T.; Takei, K.; Nishino, N.; Fujimoto, T., Solvent-dependent chiral assembling of two zinc porphyrins in a zinc-free-base-zinc trimeric porphyrin array. Chem Commun 1996, 2133-2134.

31. BothnerBy, A. A.; Dadok, J.; Johnson, T. E.; Lindsey, J. S., Molecular dynamics of covalently-linked multi-porphyrin arrays. J Phys Chem-Us 1996, 100, 17551-17557.

32. Chernook, A. V.; Rempel, U.; vonBorczyskowski, C.; Shulga, A. M.; Zenkevich, E. I., Formation and optical properties of self-organized pentameric porphyrin arrays. Chem Phys Lett 1996, 254, 229-241. 
33. Freemantle, M., Synthetic strategy yields large porphyrin arrays in one step. Chem Eng News 1996, 74, 28-30.

34. Alessio, E.; Macchi, M.; Heath, S. L.; Marzilli, L. G., Ordered supramolecular porphyrin arrays from a building block approach utilizing pyridylporphyrins and peripheral ruthenium complexes and identification of a new type of mixed-metal building block. Inorg Chem 1997, 36, 5614-5623.

35. Drain, C. M.; Shi, X.; Gong, X.; Nifiatis, F.; Ruta, V.; Vasenko, A., Formation of selfassembled porphyrin arrays in 1-, 2-, \& 3-dimensions. Abstr Pap Am Chem S 1997, 214, 338PHYS.

36. Iovine, P. M.; Kellett, M. A.; Therien, M. J., Synthesis and characterization of cofacial porphyrin-quinone systems to investigate electronic coupling and photoinduced electron transfer through stacked aromatic arrays. Abstr Pap Am Chem S 1997, 213, 283-INOR.

37. Biemans, H. A. M.; Rowan, A. E.; Verhoeven, A.; Vanoppen, P.; Latterini, L.; Foekema, J.; Schenning, A. P. H. J.; Meijer, E. W.; de Schryver, F. C.; Nolte, R. J. M., Hexakis porphyrinato benzenes. A new class of porphyrin arrays. J Am Chem Soc 1998, 120, 11054-11060.

38. Burrell, A. K.; Allwood, J.; Jones, B. M.; Hall, S. B.; Officer, D. L.; Reid, D. C. W.; Wild, K. Y., Controlling the structure of supramolecular porphyrin arrays. Abstr Pap Am Chem S 1998, 215, U792-U792.

39. Burrell, A. K.; Officer, D. L.; Reid, D. C. W.; Wild, K. Y., Controlling the structure of supramolecular porphyrin arrays. Angew Chem Int Edit 1998, 37, 114-117.

40. Chambron, J. C.; Collin, J. P.; Dalbavie, J. O.; Dietrich-Buchecker, C. O.; Heitz, V.; Odobel, F.; Solladie, N.; Sauvage, J. P., Rotaxanes and other transition metal-assembled porphyrin arrays for long-range photoinduced charge separation. Coordin Chem Rev 1998, 178, 12991312.

41. Drain, C. M.; Nifiatis, F.; Vasenko, A.; Batteas, J. D., Porphyrin tessellation by design: Metalmediated self-assembly of large arrays and tapes. Angew Chem Int Edit 1998, 37, 2344-2347.

42. Flamigni, L.; Barigelletti, F.; Armaroli, N.; Collin, J. P.; Sauvage, J. P.; Williams, J. A. G., Photoinduced processes in highly coupled multicomponent arrays based on a ruthenium(ii)bis(terpyridine) complex and porphyrins. Chem-Eur J 1998, 4, 1744-1754.

43. Akimoto, S.; Yamazaki, T.; Yamazaki, I.; Nakano, A.; Osuka, A., Ultrafast excitation transfer and relaxation in linear and crossed-linear arrays of porphyrins. Pure Appl Chem 1999, 71, 2107-2115.

44. Alessio, E.; Geremia, S.; Mestroni, S.; Srnova, I.; Slouf, M.; Gianferrara, T.; Prodi, A., 
Porphyrin "flying-saucers": Solid state and solution structure of a novel pentameric array of axially-ligated canted porphyrins. Inorg Chem 1999, 38, 2527-+.

45. Beavington, R.; Burn, P. L., Bis-porphyrin arrays. Part 1. The synthesis of meso-halophenyl porphyrin-alpha-diones. J Chem Soc Perk T 1 1999, 583-592.

46. Burrell, A. K.; Jones, B. M.; Hall, S. B.; Officer, D. L.; Reid, D. C. W.; Wild, K. Y., The supramolecular assembly of porphyrin arrays. J Incl Phenom Macro 1999, 35, 185-190.

47. Chichak, K.; Branda, N. R., Self-assembly of a linear multicomponent porphyrin array through axial coordination. Chem Commun 1999, 523-524.

48. Crossley, M. J.; McDonald, J. A., Fused porphyrin-imidazole systems: New building blocks for synthesis of porphyrin arrays. J Chem Soc Perk T 1 1999, 2429-2431.

49. Darling, S. L.; Mak, C. C.; Bampos, N.; Feeder, N.; Teat, S. J.; Sanders, J. K. M., A combined covalent and coordination approach to dendritic multiporphyrin arrays based on ruthenium(ii) porphyrins. New J Chem 1999, 23, 359-364.

50. Drain, C. M., Porphyrin tessellation by design: Metal mediated self-assembly of arrays and tapes. Abstr Pap Am Chem S 1999, 217, U957-U958.

51. Fan, J.; Whiteford, J. A.; Olenyuk, B.; Levin, M. D.; Stang, P. J.; Fleischer, E. B., Selfassembly of porphyrin arrays via coordination to transition metal bisphosphine complexes and the unique spectral properties of the product metallacyclic ensembles. J Am Chem Soc 1999, $121,2741-2752$.

52. Giribabu, L.; Rao, T. A.; Maiya, B. G., "Axial-bonding"-type hybrid porphyrin arrays: Synthesis, spectroscopy, electrochemistry, and singlet state properties. Inorg Chem 1999, 38, 4971-4980.

53. Graca, M.; Vicente, H.; Jaquinod, L.; Smith, K. M., Oligomeric porphyrin arrays. Chem Commun 1999, 1771-1782.

54. Alessio, E.; Ciani, E.; lengo, E.; Kukushkin, V. Y.; Marzilli, L. G., Stepwise assembly of unsymmetrical supramolecular arrays containing porphyrins and coordination compounds. Inorg Chem 2000, 39, 1434-1443.

55. Ambroise, A.; Li, J. Z; Yu, L. H.; Lindsey, J. S., A self-assembled light-harvesting array of seven porphyrins in a wheel and spoke architecture. Org Lett 2000, 2, 2563-2566.

56. Aratani, N.; Osuka, A.; Kim, Y. H.; Jeong, D. H.; Kim, D., Extremely long, discrete mesomeso-coupled porphyrin arrays. Angew Chem Int Edit 2000, 39, 1458-+. 
57. Beavington, R.; Burn, P. L., Bis-porphyrin arrays. Part 3. The synthesis of model bisporphyrin dimers and an electrochemical study. J Chem Soc Perk T $12000,1231-1240$.

58. Beavington, R.; Burn, P. L., Bis-porphyrin arrays. Part 2. The synthesis of asymmetrically substituted bis-porphyrins. J Chem Soc Perk T 1 2000, 605-609.

59. Bhuiyan, A. A.; Osuka, A.; Bocian, D. F., Resonance raman spectra of meso, meso-linked porphyrin arrays. Abstr Pap Am Chem S 2000, 219, U812-U812.

60. Bhuiyan, A. A.; Seth, J.; Yoshida, N.; Osuka, A.; Bocian, D. F., Resonance raman characterization of excitonically coupled meso,meso-linked porphyrin arrays. $J$ Phys Chem $B$ 2000, 104, 10757-10764.

61. Chichak, K.; Branda, N. R., The metal-directed self-assembly of three-dimensional porphyrin arrays. Chem Commun 2000, 1211-1212.

62. Cho, H. S.; Song, N. W.; Kim, Y. H.; Jeoung, S. C.; Hahn, S.; Kim, D.; Kim, S. K.; Yoshida, N.; Osuka, A., Ultrafast energy relaxation dynamics of directly linked porphyrin arrays. J Phys Chem A 2000, 104, 3287-3298.

63. Clausen, C.; Gryko, D. T.; Yasseri, A. A.; Diers, J. R.; Bocian, D. F.; Kuhr, W. G.; Lindsey, J. S., Investigation of tightly coupled porphyrin arrays comprised of identical monomers for multibit information storage. J Org Chem 2000, 65, 7371-7378.

64. Guldi, D. M.; Luo, C. P.; Da Ros, T.; Prato, M.; Dietel, E.; Hirsch, A., Photoinduced electron transfer in multicomponent arrays of a pi-stacked fullerene porphyrin dyad and diazabicyclooctane or a fulleropyrrolidine ligand. Chem Commun 2000, 375-376.

65. Harmjanz, M.; Scott, M. J., Facile synthesis of stacked, heteronuclear porphyrin arrays with varied architectures. Inorg Chem 2000, 39, 5428-5429.

66. Aratani, N.; Osuka, A., Synthesis of meso-meso linked hybrid porphyrin arrays by pdcatalyzed cross-coupling reaction. Org Lett 2001, 3, 4213-4216.

67. Aratani, N.; Osuka, A., A new strategy for construction of covalently linked giant porphyrin arrays with one, two, and three dimensionally arranged architectures. B Chem Soc Jpn 2001, $74,1361-1379$.

68. Aratani, N.; Osuka, A., Monodisperse giant porphyrin arrays. Macromol Rapid Comm 2001, 22, 725-740.

69. Aratani, N.; Tsuda, A.; Osuka, A., Discrete giant porphyrin arrays: Challenges to molecular size, length and the extent of electronic pi-conjugation. Synlett 2001, 1663-1674. 
70. Foekema, J.; Schenning, A. P. H. J.; Vriezema, D. M.; Benneker, F. B. G.; Norgaard, K.; Kroon, J. K. M.; Bjornholm, T.; Feiters, M. C.; Rowan, A. E.; Nolte, R. J. M., Synthesis of multi porphyrin arrays and study of their self-assembly behaviour at the air-water interface. $J$ Phys Org Chem 2001, 14, 501-512.

71. Hanks, T. W.; Bergman, B.; Dillon, P., Design and synthesis of porphyrin-containing arrays on polypyrrole surfaces. Synthetic Met 2001, 121, 1431-1432.

72. Ikeda, C.; Tanaka, Y.; Fujihara, T.; Ishii, Y.; Ushiyama, T.; Yamamoto, K.; Yoshioka, N.; Inoue, $\mathrm{H}$., Self-assembly of a porphyrin array via the molecular recognition approach: Synthesis and properties of a cyclic zinc(ii) porphyrin trimer based on coordination and hydrogen bonding. Inorg Chem 2001, 40, 3395-3405.

73. Baldini, L.; Hunter, C. A., Self-assembly of porphyrin arrays. Adv Inorg Chem 2002, 53, 213259.

74. Cheng, K. F., Hierarchical self-assembly of photonic materials: Supramolecular porphyrinporphyrazine arrays via square planar metal ion linkers. Abstr Pap Am Chem S 2002, 224, U720-U720.

75. Chi, N.; Zhang, X. M.; Milic, T.; Yablon, D. G.; Drain, C. M.; Flynn, G. W.; Batteas, J. D., Self-assembly and fluorescence studies of porphyrin supramolecular arrays on surfaces. Abstr Pap Am Chem S 2002, 223, U428-U429.

76. Drain, C. M.; Batteas, J. D.; Flynn, G. W.; Milic, T.; Chi, N.; Yablon, D. G.; Sommers, H., Designing supramolecular porphyrin arrays that self-organize into nanoscale optical and magnetic materials. P Natl Acad Sci USA 2002, 99, 6498-6502.

77. Flamigni, L.; Marconi, G.; Dixon, I. M.; Collin, J. P.; Sauvage, J. P., Switching of electron- to energy-transfer by selective excitation of different chromophores in arrays based on porphyrins and a polypyridyl iridium complex. J Phys Chem B 2002, 106, 6663-6671.

78. Fletcher, J. T.; Therien, M. J., Strongly coupled porphyrin arrays featuring both, pi-cofacial and linear-pi-conjugative interactions. Inorg Chem 2002, 41, 331-341. 